\title{
A NICU Respiratory Therapist's Christmas Wish List
}

Rob Graham, R.R.T./N.R.C.P.

I dedicate this column to the late Dr. Andrew (Andy) Shennan, the founder of the perinatal program at Women's College Hospital (now at Sunnybrook Health Sciences Centre). To my teacher, my mentor and the man I owe my career as it is to, thank you. You have earned your place where there are no hospitals and no NICUs, where all the babies do is laugh and giggle and sleep.

"It is that time of year again, and while Christmas is typically thought of as for children, adults can dream of wished gifts under the tree. These gifts will not be found under any tree, but they represent the dreams of many an RRT."

It is that time of year again, and while Christmas is typically thought of as for children, adults can dream of wished gifts under the tree. These gifts will not be found under any tree, but they represent the dreams of many an RRT.

Fully integrated and automated saturation $\left(\mathrm{SpO}_{2}\right)$ monitoring and $\mathrm{FiO}_{2}$ control

For over 70 years, we have known that too much oxygen is a major risk factor for retinopathy of prematurity. While the alarm limits and targeted $\mathrm{SpO}_{2}$ ranges differ between NICUs, the reality is staffing issues mean that these targets are often exceeded, even with the most diligent monitoring. One bedside nurse or RRT cannot be in more than one place at a time, and unless a baby is assigned "one-to-one," their caregivers cannot be continuously at their bedsides. Too often, the results are alarm fatigue. This results in over-targeting or the adjustment of alarm limits outside targeted ranges. Histogram analysis of $\mathrm{SpO}_{2}$ too often shows an inordinate amount of time with $\mathrm{SpO}_{2}$ above $95 \%$. The reliability of available monitors has significantly improved over the past decade, and automatic $\mathrm{FiO}_{2}$ adjustment is available on some ventilators. To the best of my knowledge, this technology has not made it to the bedside in NICUs.

Universal availability of third-generation oscillators.
Those who read this column regularly will know I am a proponent of high-frequency ventilation, and my first column (January 2019) addressed high-frequency oscillation with volume targeting. May the FDA grant the wishes of many American RRTs by approving at least one of these machines for American use.

"Those who read this column regularly will know I am a proponent of highfrequency ventilation, and my first column (January 2019) addressed high-frequency oscillation with volume targeting. May the FDA grant the wishes of many American RRTs by approving at least one of these machines for American use."

\section{A 2.0 jet adaptor.}

This one is rather controversial. I admit to originally nixing the making of a 2.0 LifePort ${ }^{\circledR}$ adaptor, however further thought has changed my stance. It is becoming more common to resuscitate 22-week gestation infants, and high-frequency jet ventilation appears to offer the greatest hope for favourable respiratory outcomes for these babies. While the use of a 2.0 ETT should only be for a short time due to the virtual impossibility of suctioning effectively, it can bridge the gap between resuscitation and the placement of a 2.5 ETT once there has been some dilation. This has happened once in my practice.

\section{Lower jet ventilator rates.}

The physics of gas flow dictate that very tiny babies (and 2.0 ETTs) have inherently high resistance resulting in long time constants. While jet ventilation is the best tool available to mitigate gas trapping, it is often unavoidable, even at rates of 240 .

An end to rib counting.

All too often, clinicians assess lung inflation by counting the number of ribs present on a chest film without assessing the quality of inflation. Haziness does not represent proper recruitment. Reducing PEEP in the face of gas trapping is catastrophic. High-

NEONATOLOGY TODAY is interested in publishing manuscripts from Neonatologists, Fellows, NNPs and those involved in caring for neonates on case studies, research results, hospital news, meeting announcements, and other pertinent topics.

Please submit your manuscript to: LomaLindaPublishingCompany@gmail.com 
frequency ventilation (HFV) favours more inflation to achieve an "open lung" than conventional ventilation does, i.e., 9-10 ribs (assuming the lung is well recruited) should not be considered hyperinflated when using HFV modes.

\section{Core therapists.}

There is an old saying: "jack of all trades, master of none." Many NICUs still rely on RRTs who rotate through other parts of the hospital. This is not a slight to those therapists. I believe the evidence shows that the units with the best outcomes have a core group of people managing ventilation. Given the steep learning curve, the complexity of ventilating premature infants, and their lungs' fragility, I believe strongly that these babies deserve their own RRTs. It takes at least a year of full-time work to achieve a measure of competency in the NICU. After all, you would not go to a pediatrician to manage your health as an adult; we recognize the value of sub-specialties in medicine in general; why not in mechanical ventilation? I personally would never attempt to manage an adult patient's ventilation without a full refresher/orientation to adult medicine.

\section{RRT autonomy.}

Having RRTs manage neonatal ventilation allows for closer monitoring and more timely response to changes in a baby's condition, coupled with a broad knowledge of respiratory physiology and the technology at use. Core therapists are more likely to have more autonomy in their practice by virtue of their experience.

\section{Collegiality}

Related to RRT autonomy, but on a broader scale. More involvement and sharing of best practices such as with the Vermont Oxford, Pediatrix, and Canadian Neonatal Network collaboratives can only improve the care we deliver. This also applies to interprofessional relationships within a given NICU.

\section{Timely administration of antenatal steroids.}

Nothing makes a NICU clinician's job harder than ventilating a baby whose mother has not received antenatal steroids. As the edge of viability inches down lower and lower, this becomes increasingly important. The evidence supporting antenatal steroids is overwhelming. Obstetricians, please practice accordingly.

\section{Family integrated care.}

All too often, parents are considered a nuisance in the NICU. This should never be the case, as parental involvement in a baby's care is vitally important from a developmental perspective and for better care overall. Nobody knows the baby better than parents. They can often see the cues of something going amiss before a clinician who may have never cared for their child. The best news? This one's free.

\section{Lower nitric oxide (iNO) prices}

While no one has been able to replicate Dr. Roberta Ballard's study on the use of iNO to prevent chronic lung disease, there are physiological reasons behind her success. It is also possible that discrepancies in ventilatory management and approaches may hinder reproducibility. In a socialised medical system such as the one I practice in Canada, costs must be considered when providing treatment. The current lack of evidence to support the use of
iNO in the premature population may in part be from its lack of usage and/or the relatively short duration of the treatment. Some babies present with initial pulmonary hypertension that may respond to iNO with a resulting decrease in ventilatory requirements(1). Published elsewhere in this journal is a letter urging more lenient guidelines for the use of iNO in the premature population.

\section{Early treatment and timely availability of patent ductus arte- riosis (PDA) ligation}

A PDA invariably complicates the ventilatory management of a baby and has been implicated as a contributor to necrotizing enterocolitis(2), CLD, intraventricular hemorrhage, and death(3). The risk of ROP is also increased in the presence of a PDA $(4,5)$ Delays in the surgical ligation of infants with PDA failing pharmacological treatment can only exacerbate these complications.

This raises the ongoing debate over the pharmacological treatment of PDA. There has been a fear of using indomethacin because of an increased risk of NEC; however, there is no increased NEC risk when used to treat PDA(6). Ibuprofen, on the other hand, is as effective as indomethacin and reduces the risk of $\operatorname{NEC}(7)$. If ventilation is a concern, one might elect to delay NSAID therapy in favour of steroid prophylaxis. I submit that if properly, gently ventilated, the risk of ROP and other PDA related sequelae outweigh the benefit of steroid prophylaxis. Acetaminophen has been shown to be effective in PDA treatment and can be used when NSAID therapy is contra-indicated, or steroid prophylaxis is a priority $(8,9)$.

\section{"If ventilation is a concern, one might elect to delay NSAID therapy in favour of steroid prophylaxis. I submit that if properly, gently ventilated, the risk of ROP and other PDA related sequelae outweigh the benefit of steroid prophylaxis."}

The problem at the bedside is that PDA presents as desaturation/ labile $\mathrm{FiO}_{2}$ especially if the $\mathrm{SpO}_{2}$ sensor is not positioned at a preductal site. The reaction is to increase $\mathrm{FiO}_{2}$ which increases the $\mathrm{PaO}_{2}$ of blood, reaching the eye and brain. That, in turn, increases the risks of both ROP and peri-ventricular bleeds through reperfusion injury(9). I might add the last reference is a course on the physiology of oxygen in the premature infant and pulse oximetry all in one.

Having said all this, the question of to treat or not to treat PDAs remains controversial at best and unanswered at worse. Studies have indicated interventions succeed in ductal closure but may not have any other benefit.(10) The latter studies do not appear to examine the risk of NEC independently.

I do not think Santa's sleigh has room for all of this, but one can hope. Every year new technology emerges that promises to give us better outcomes. All too often, it is we clinicians who are behind the curve. 


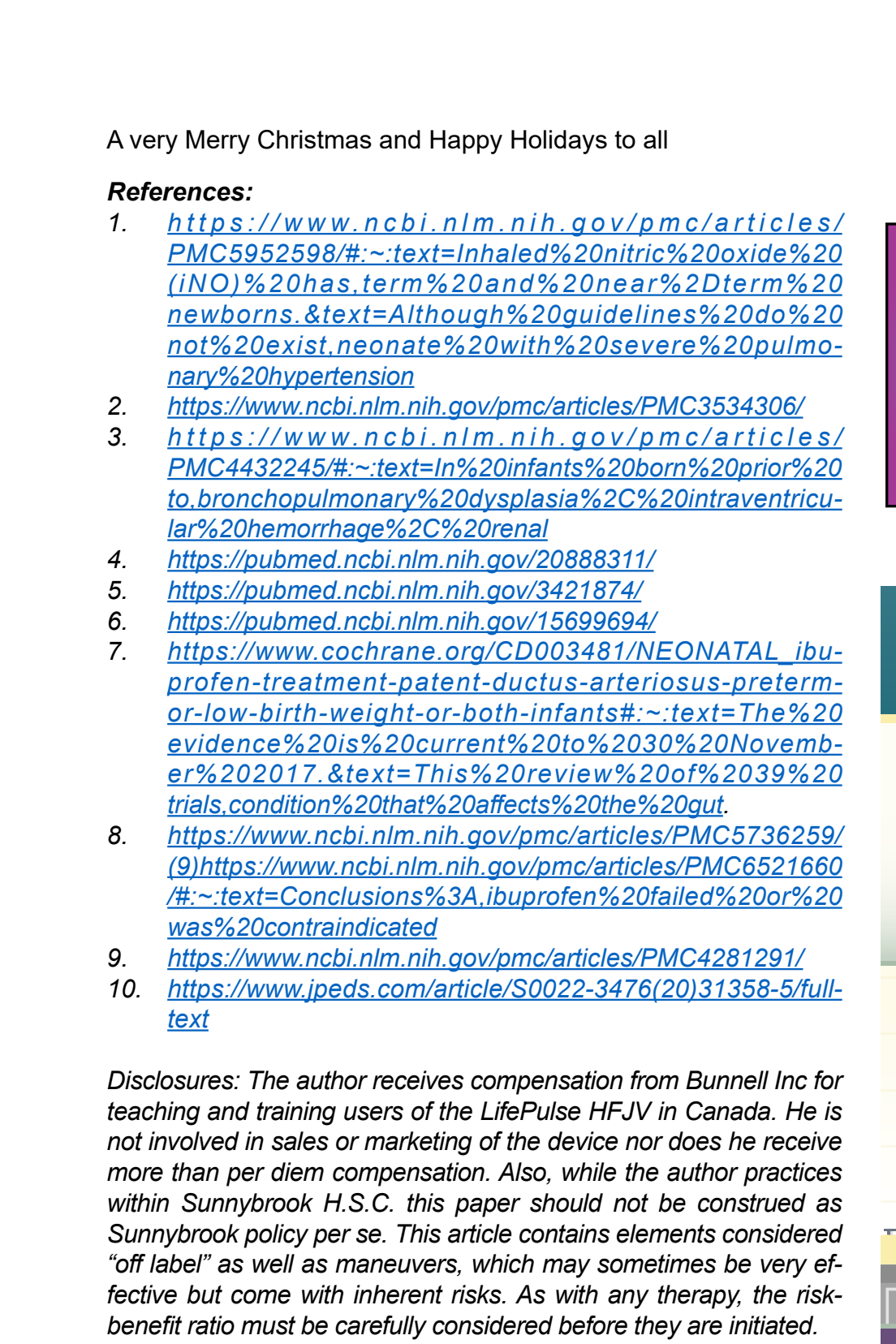

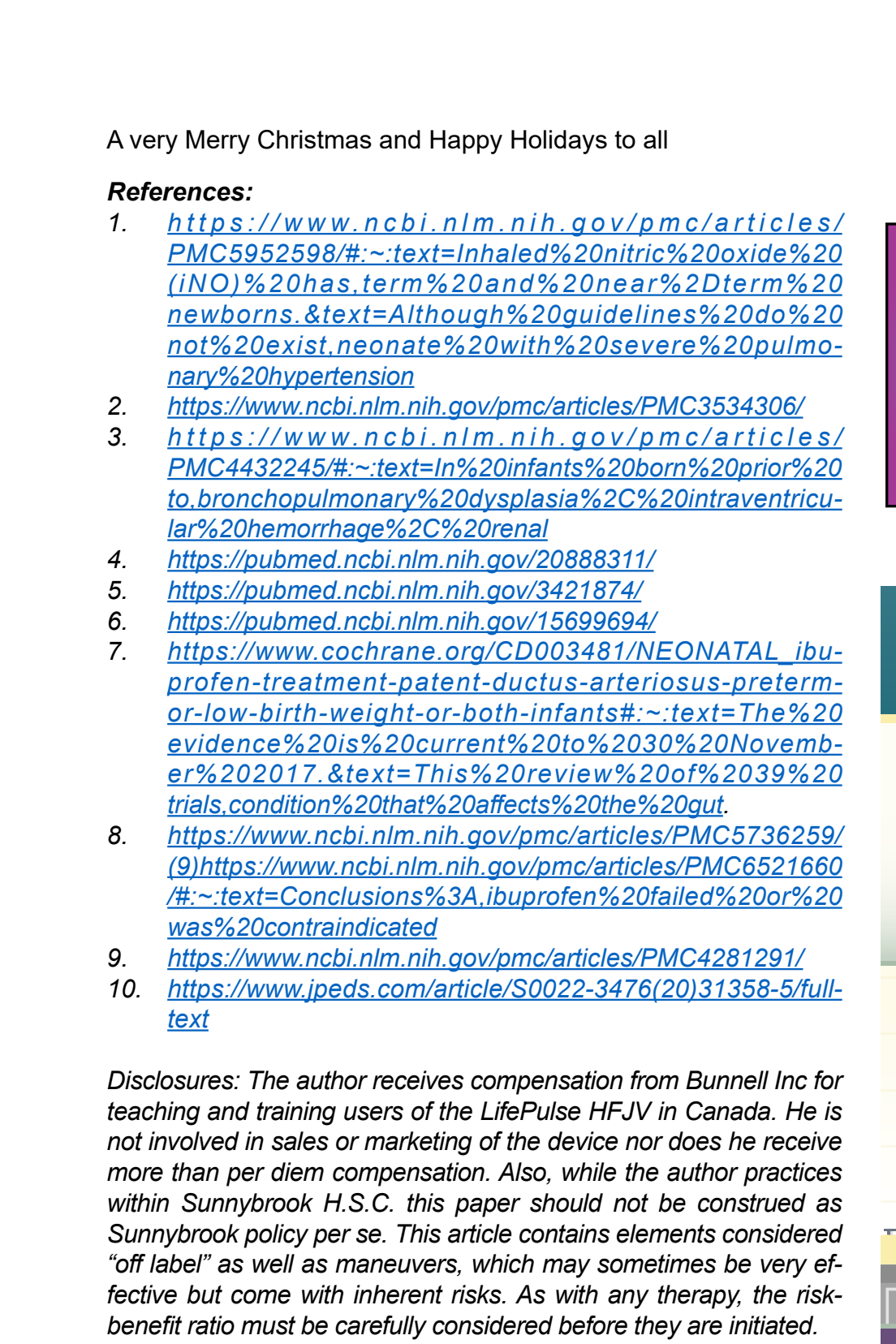

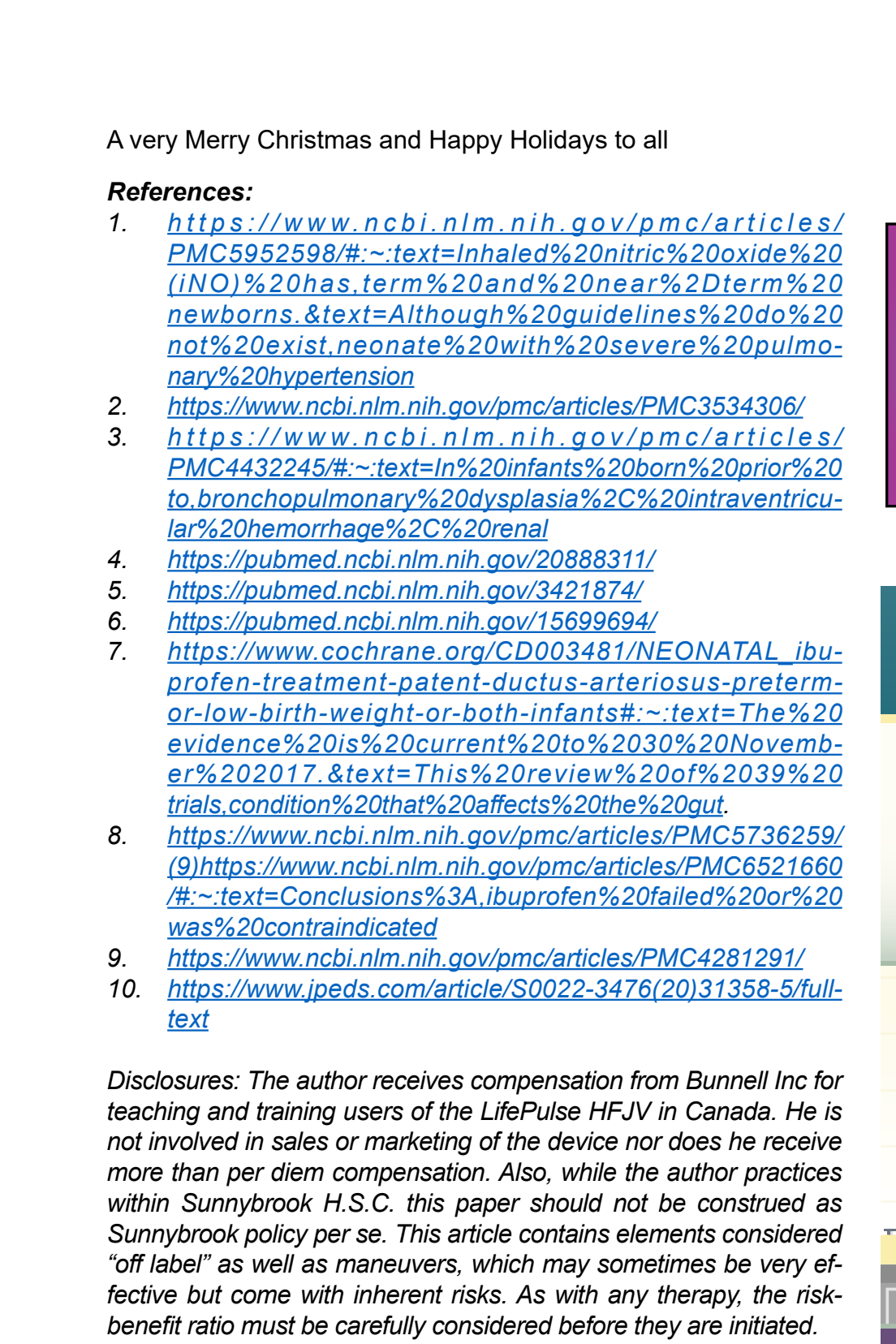

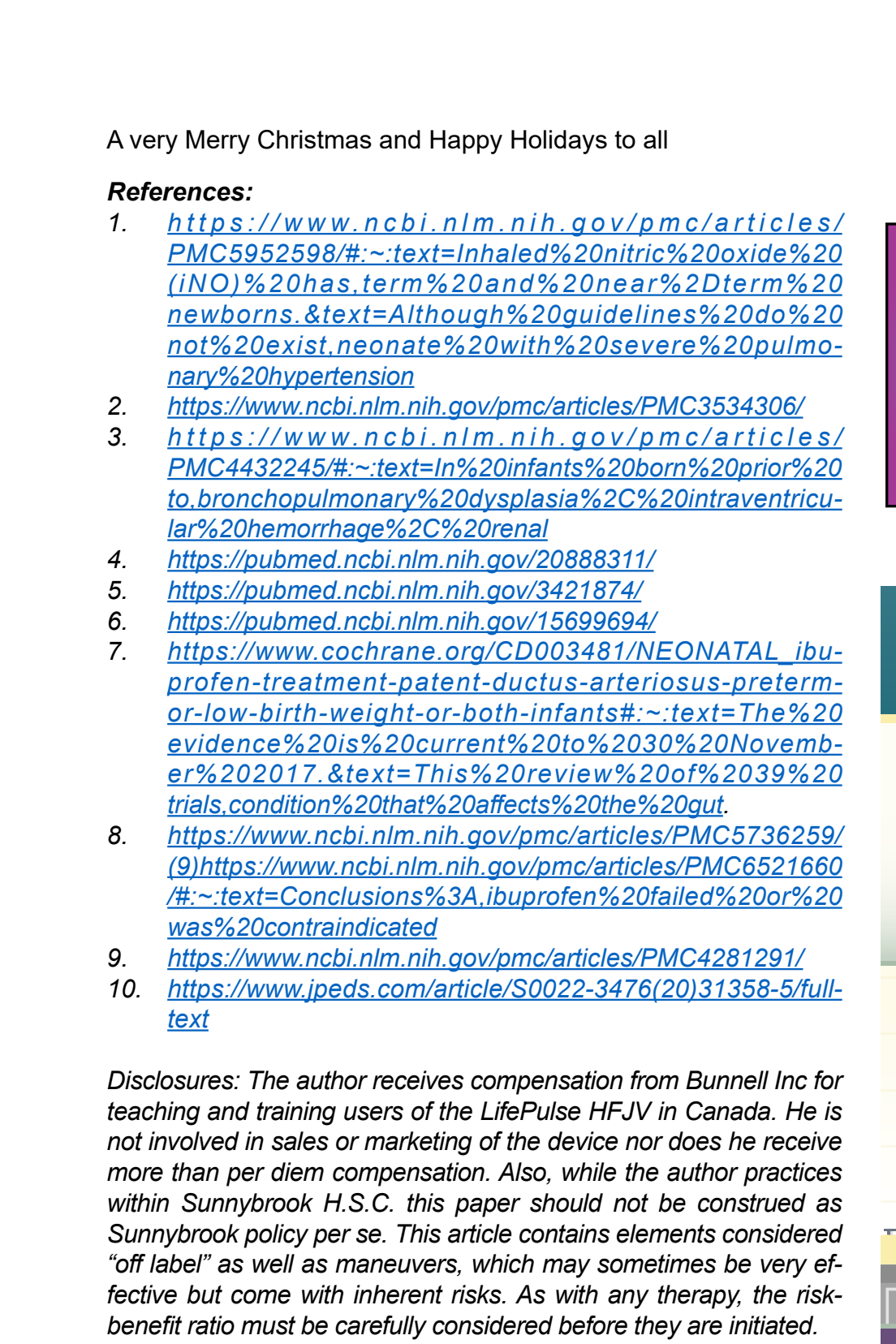

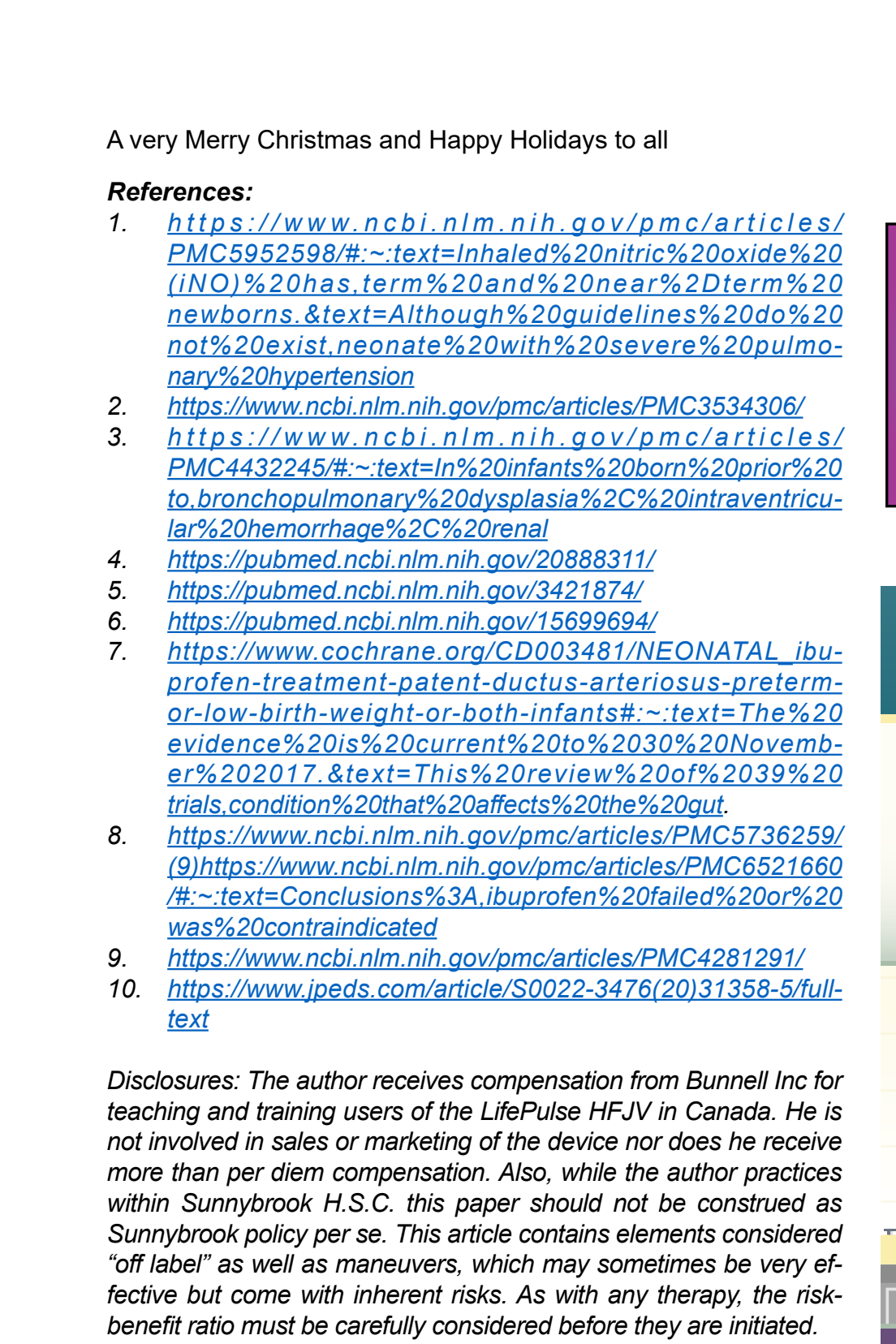

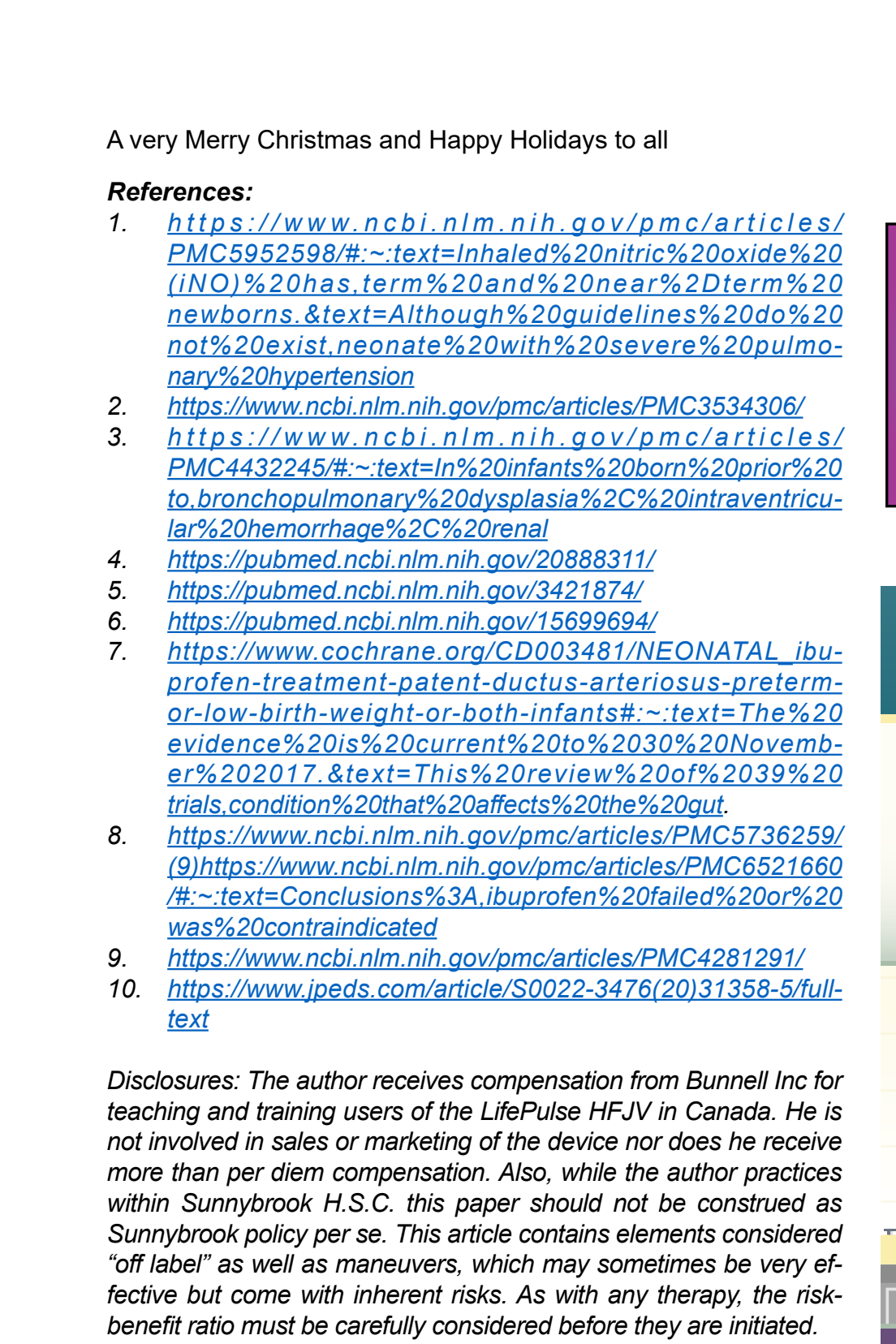

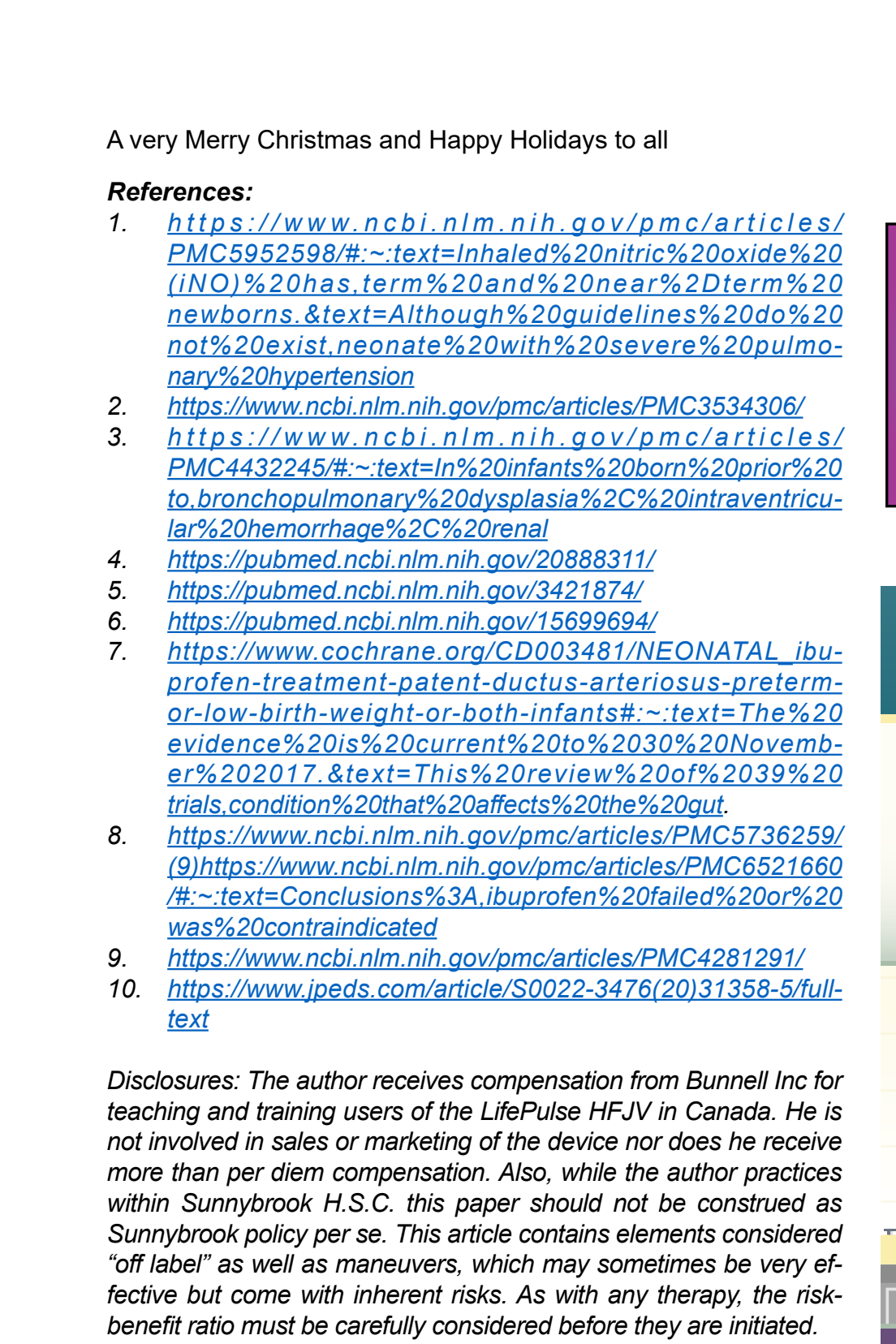

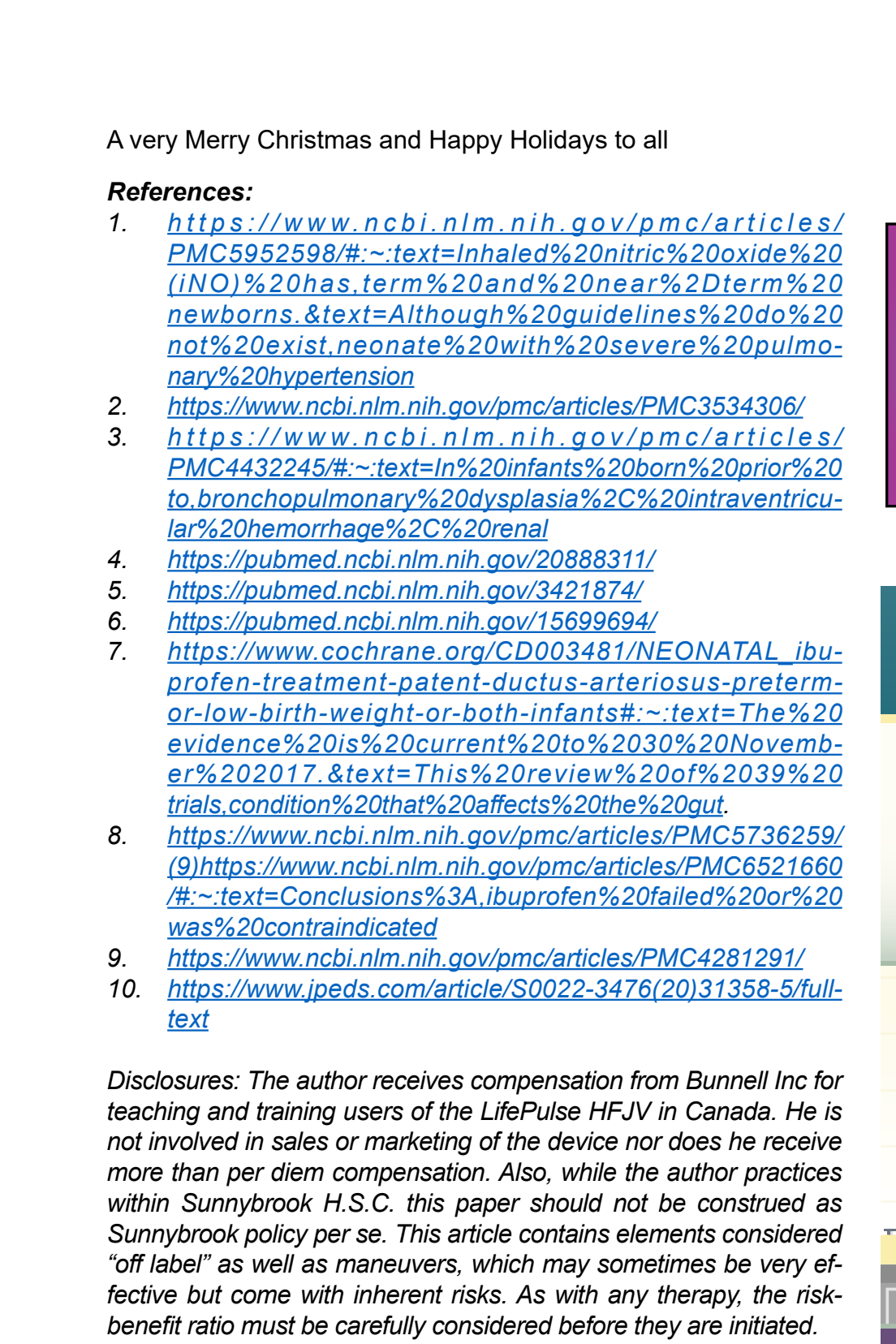

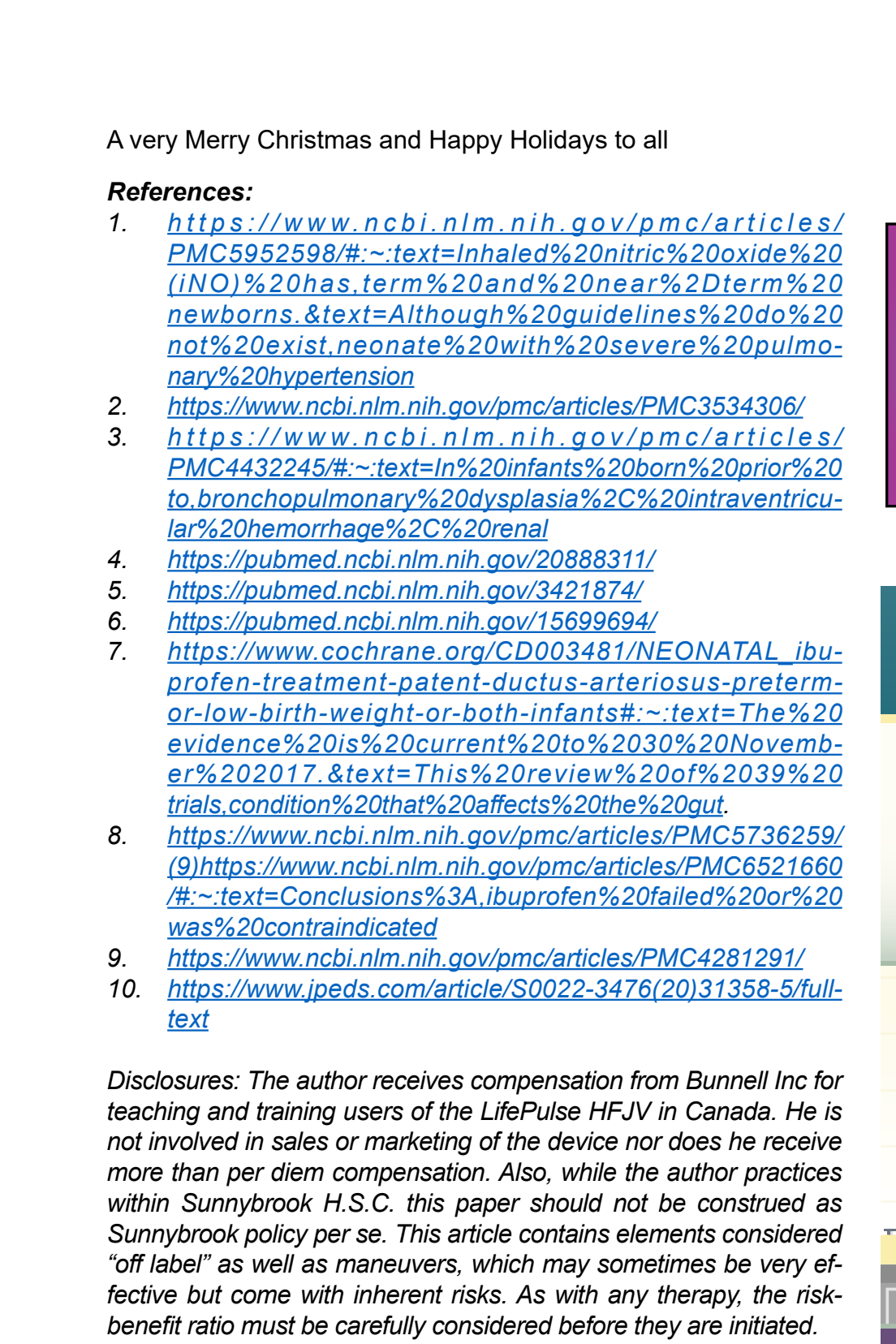

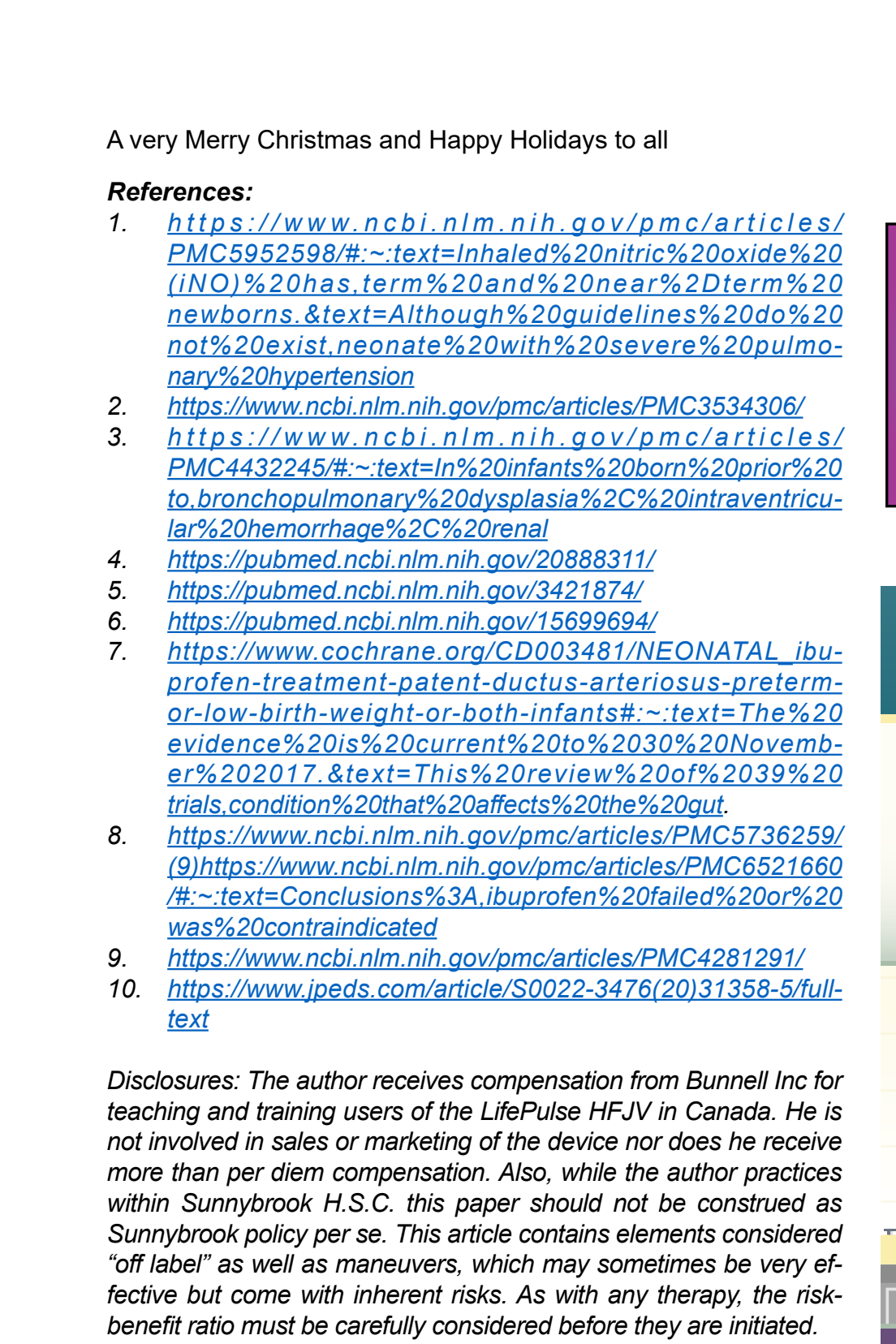

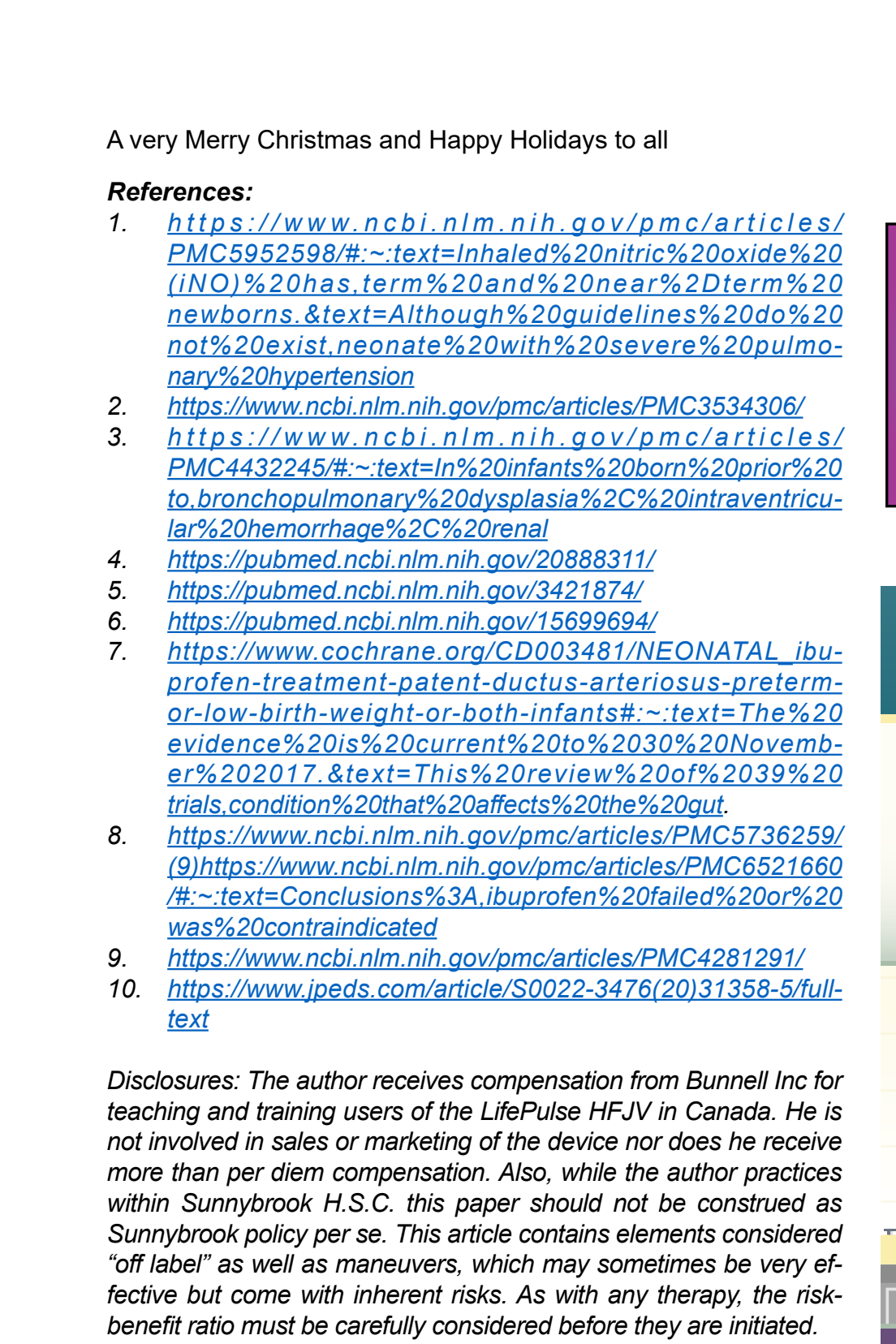

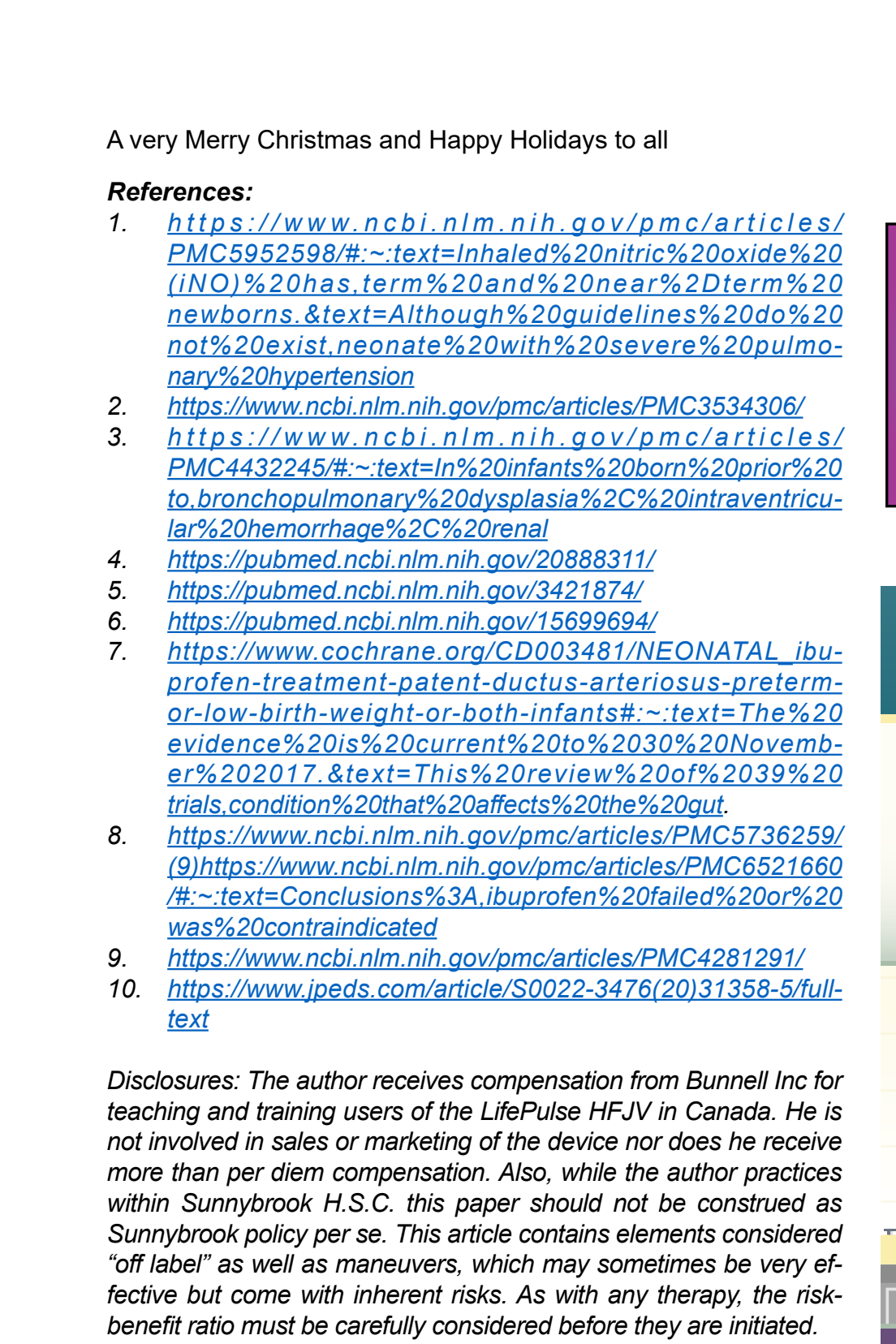

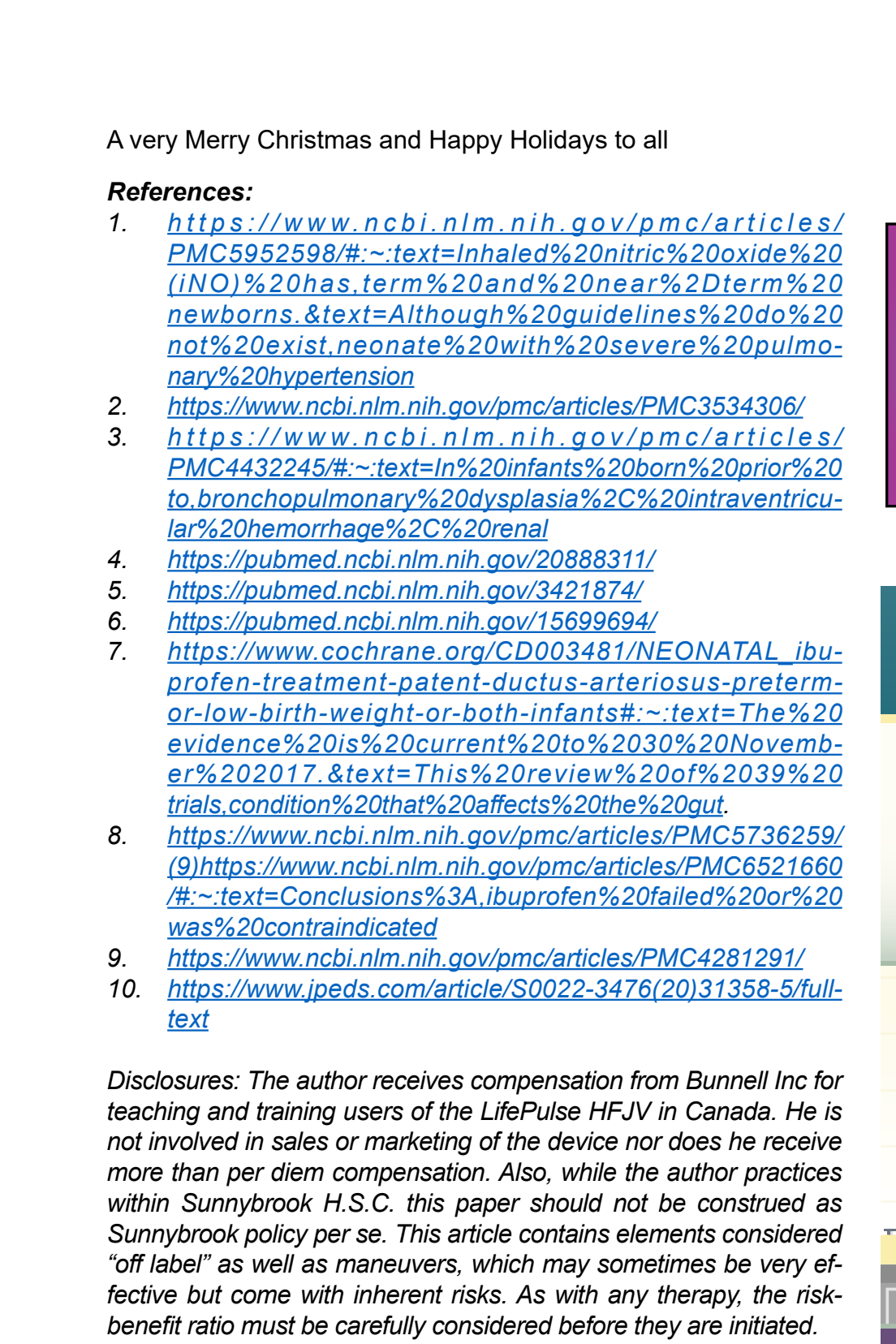

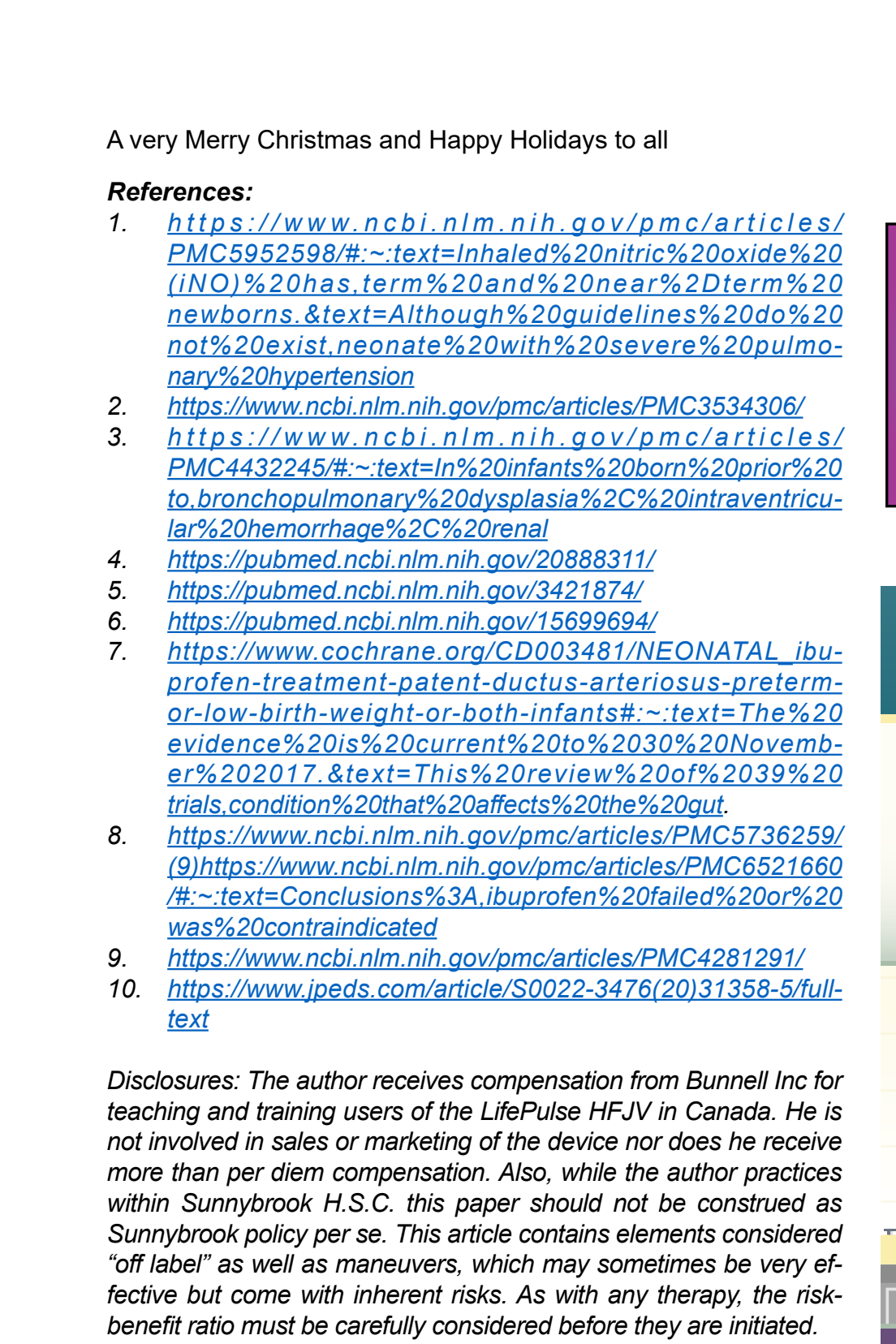

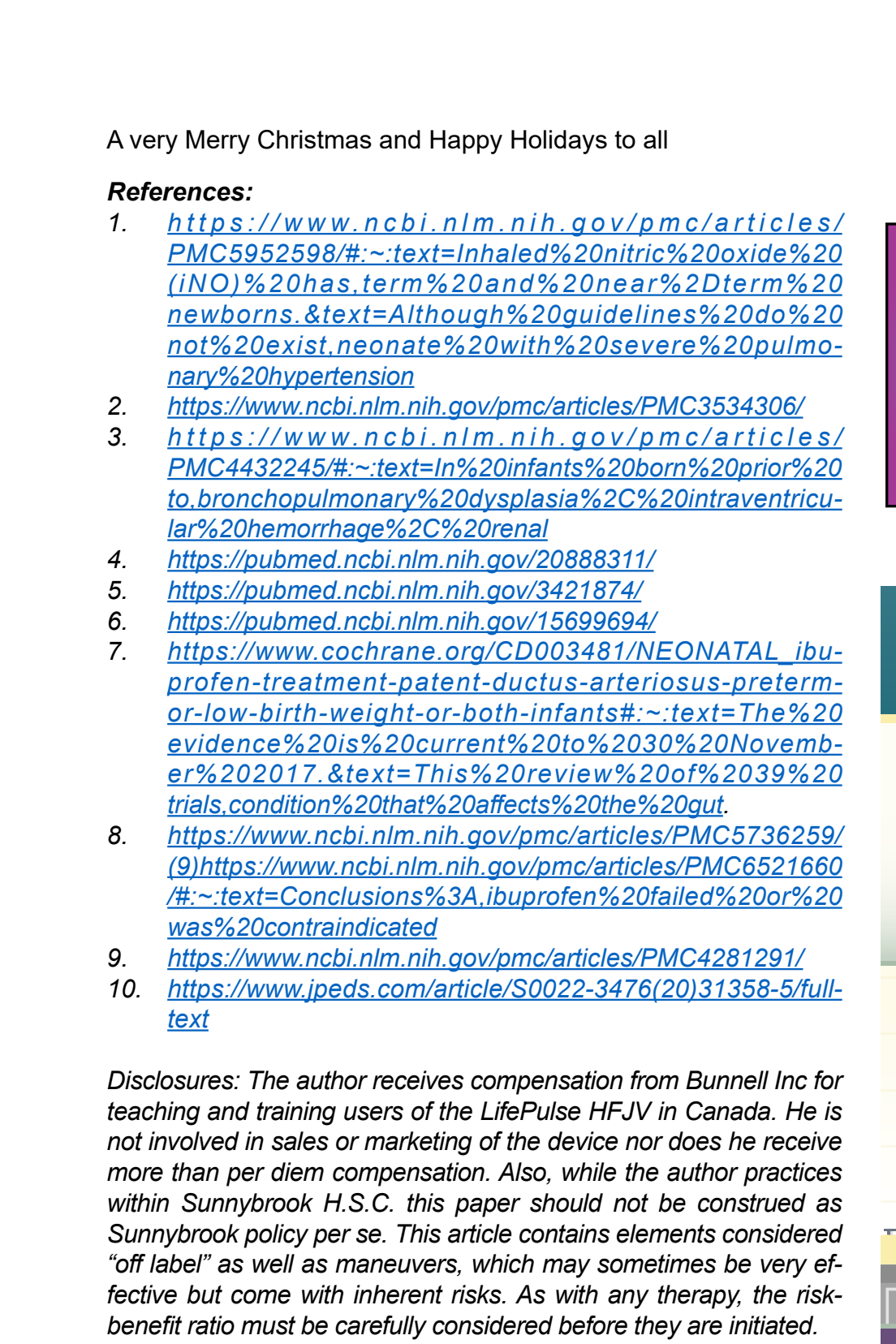

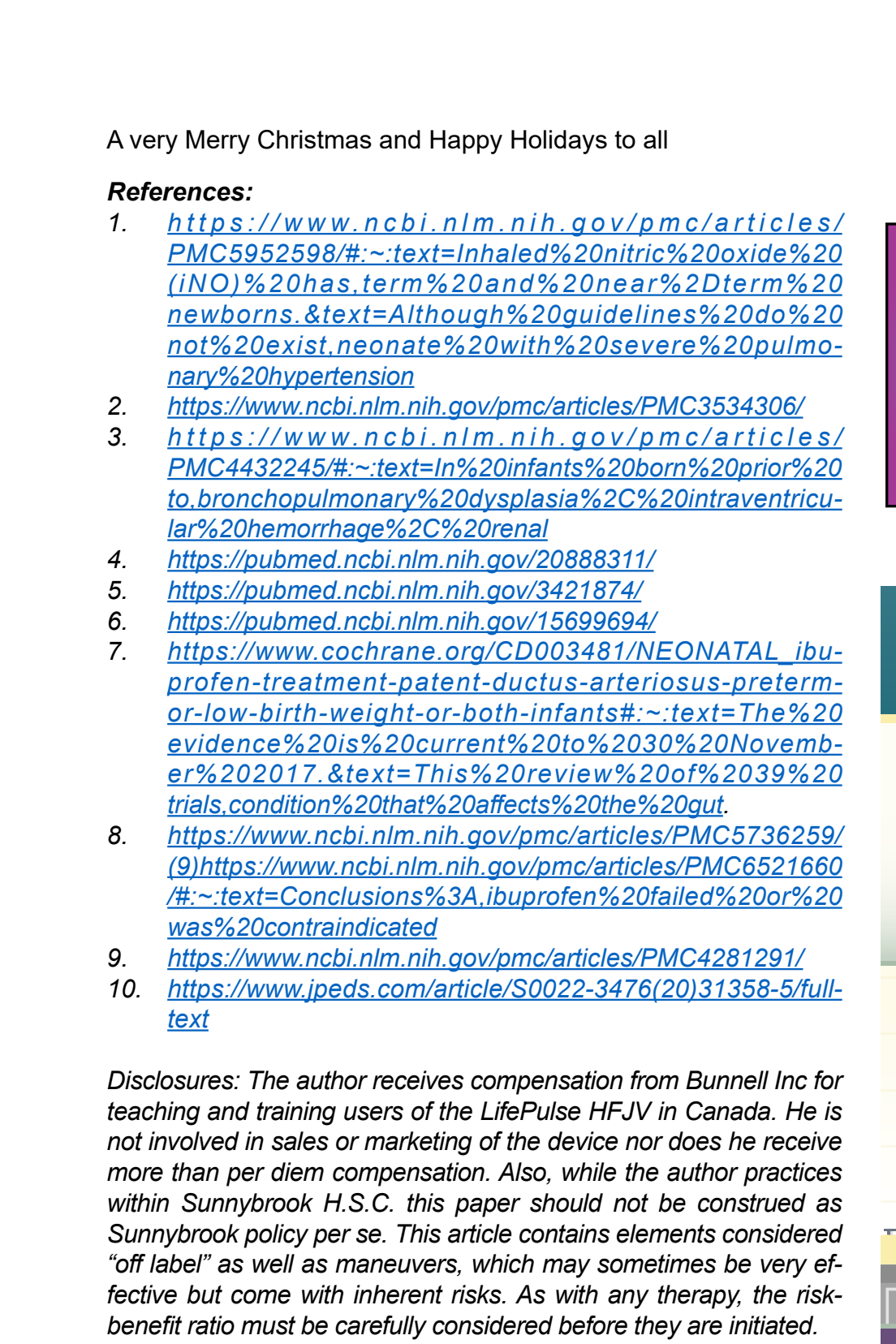

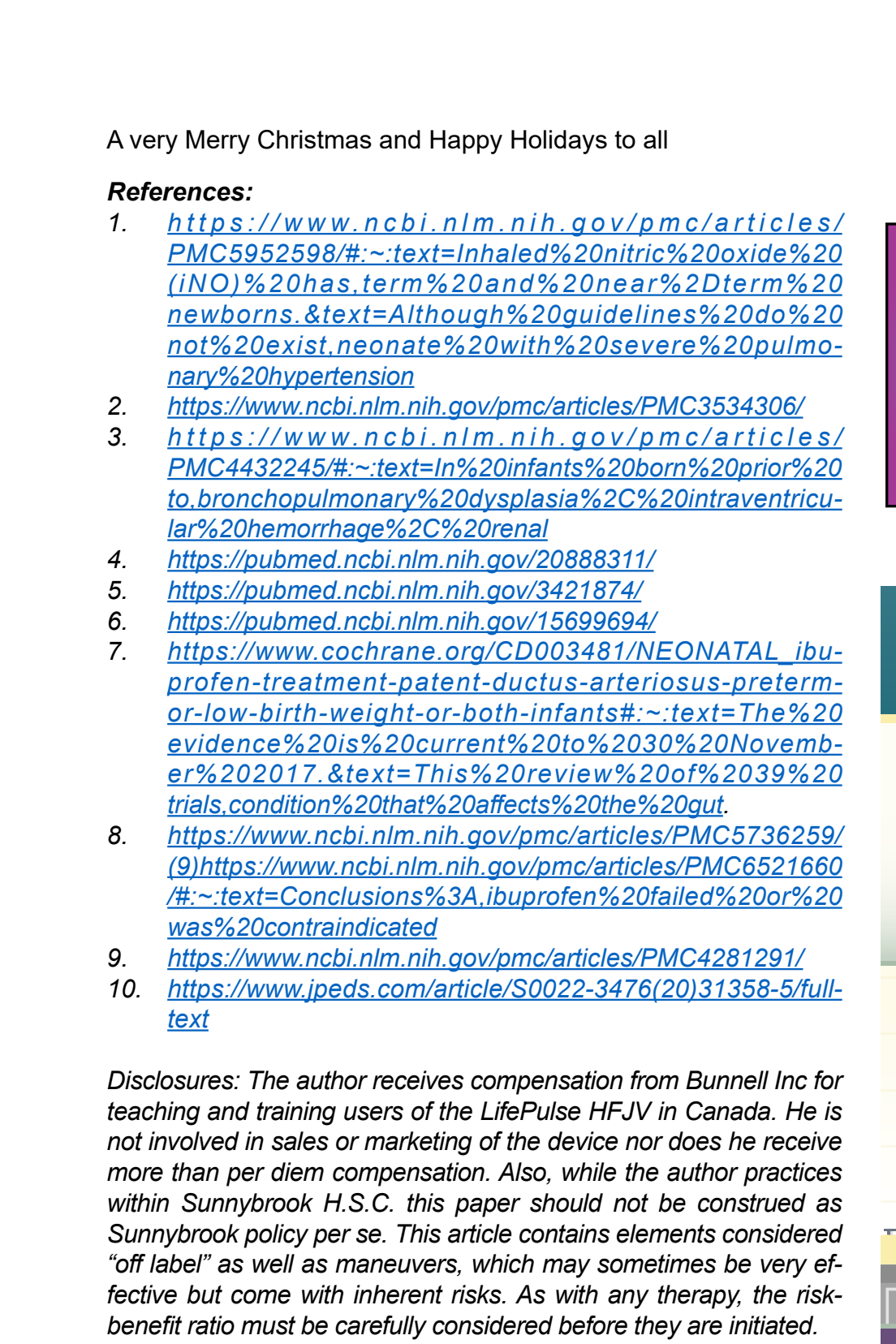

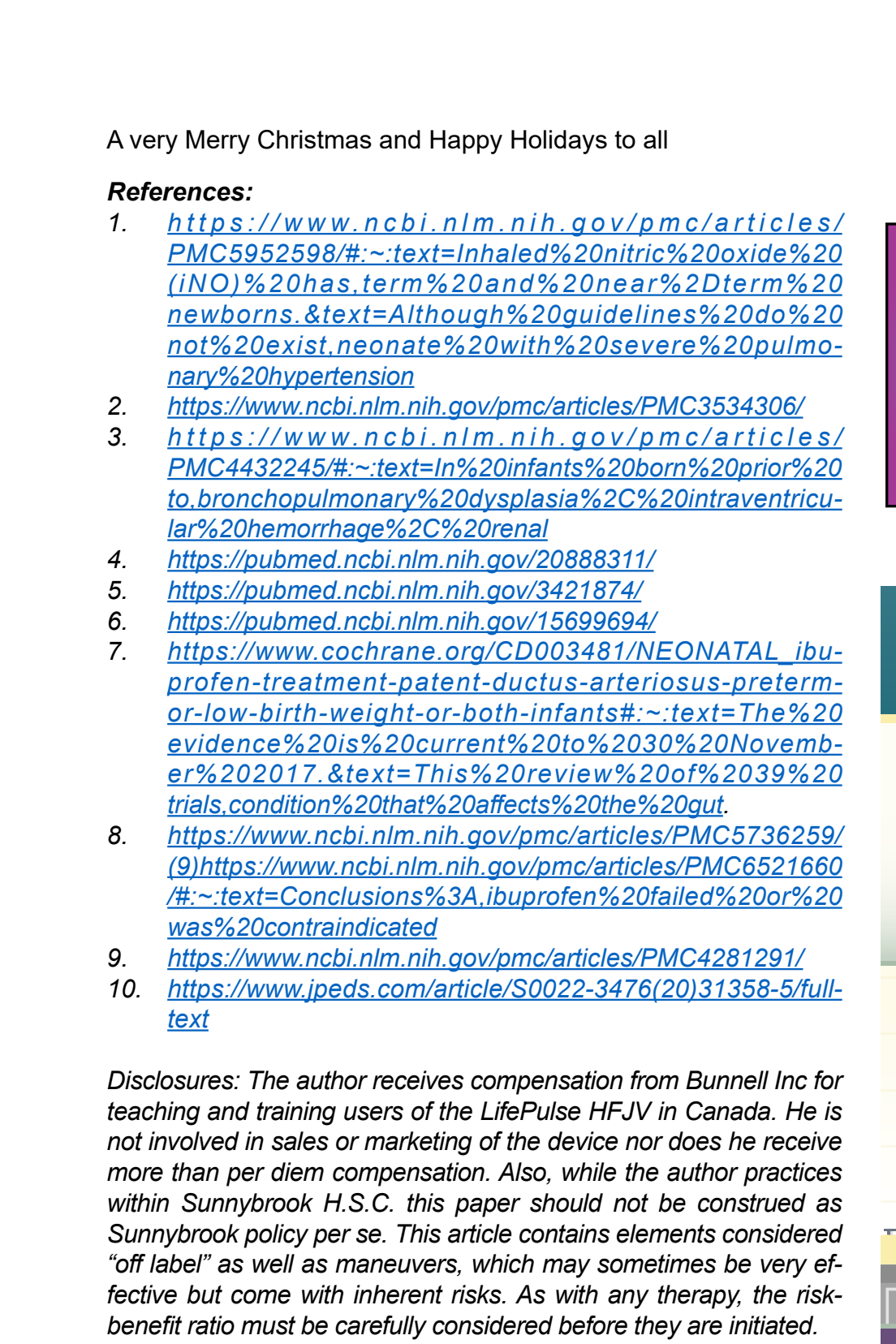

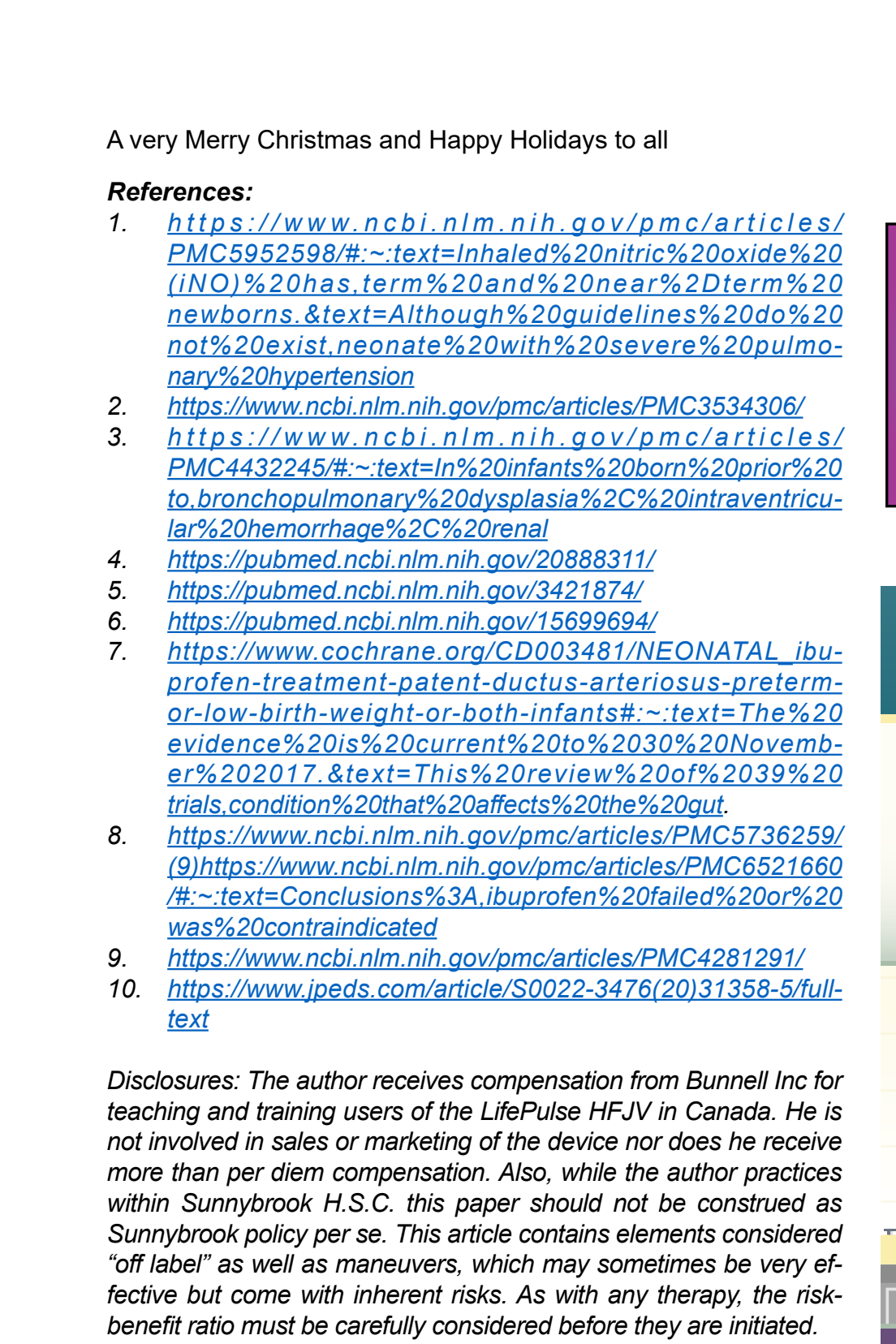

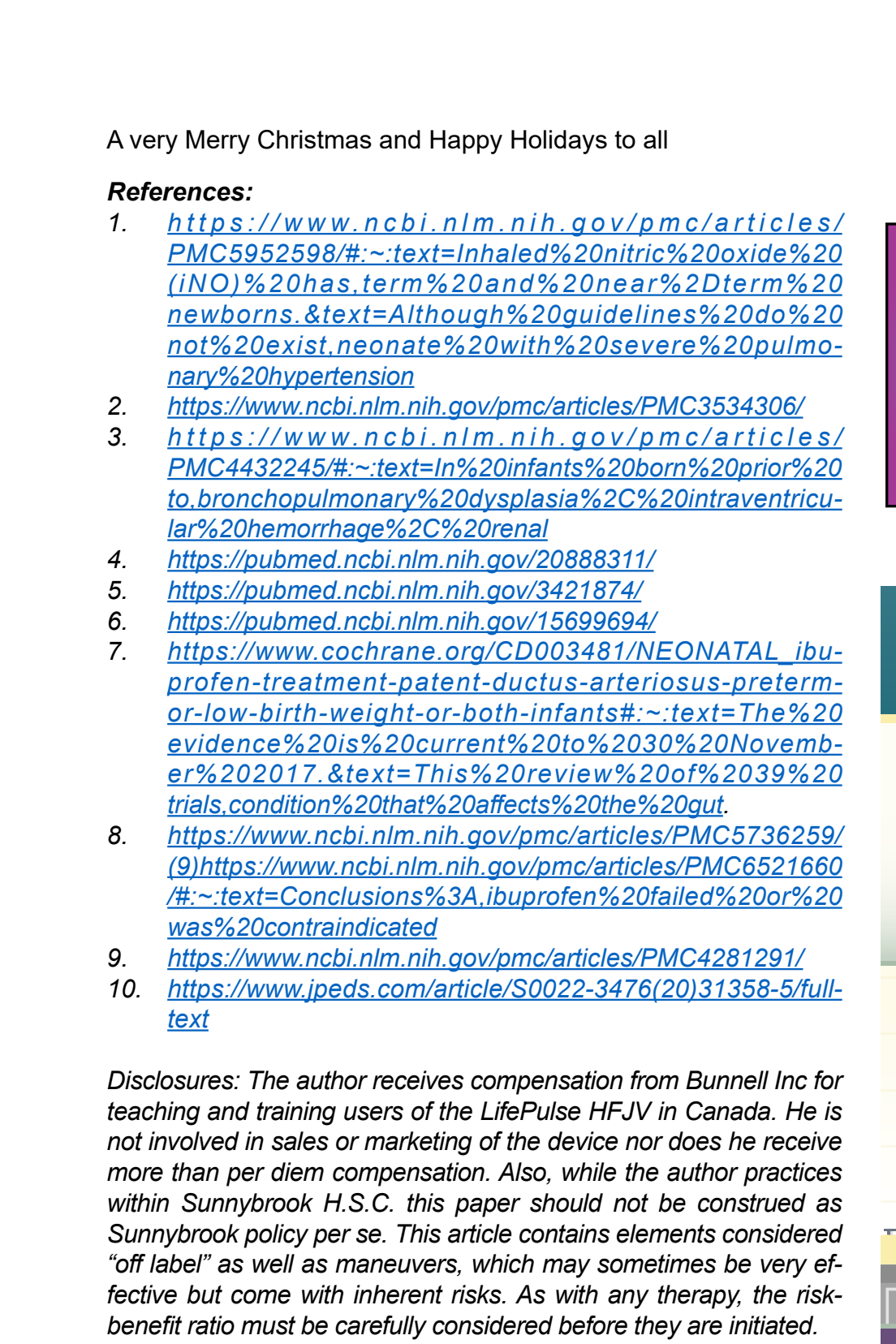

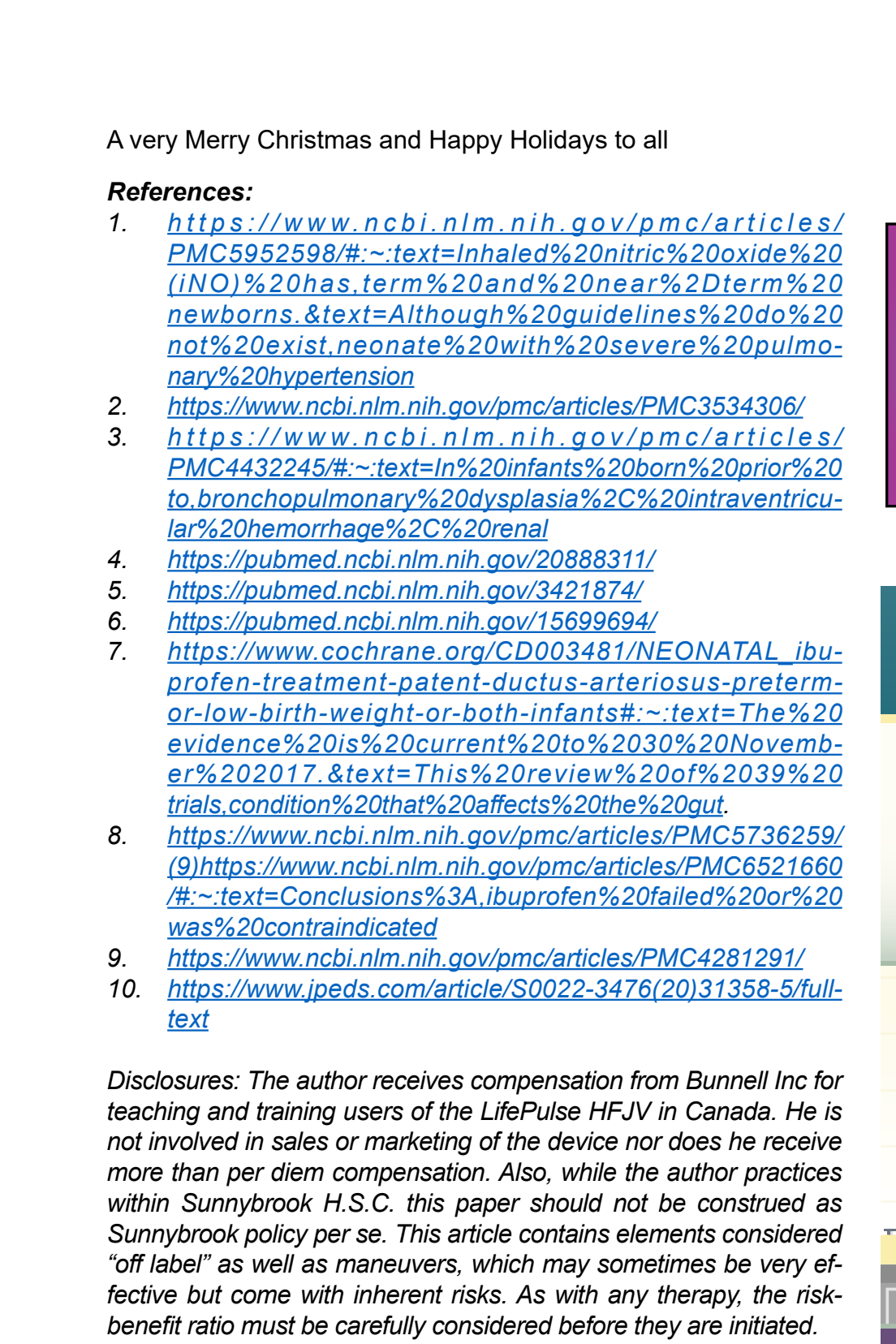

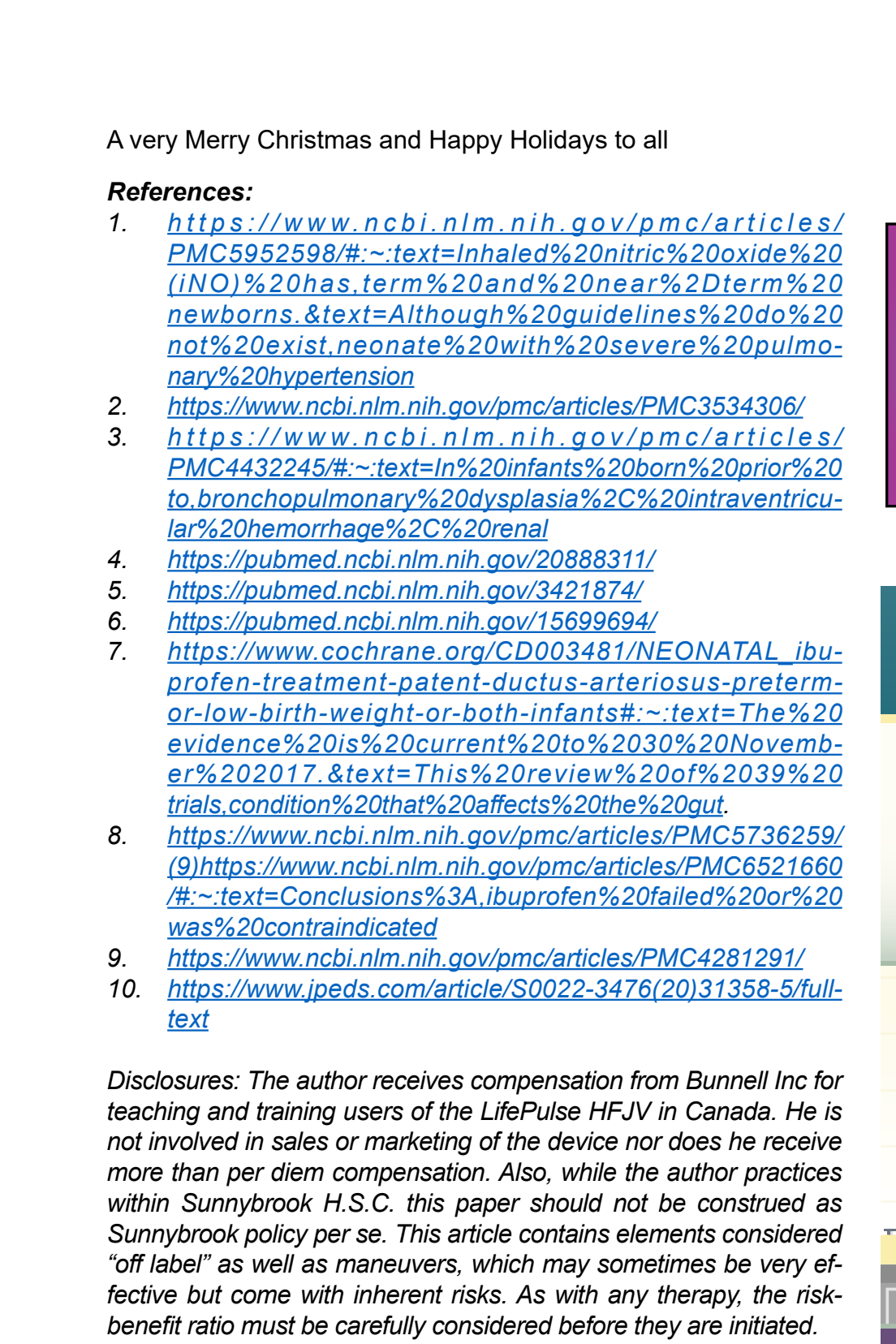

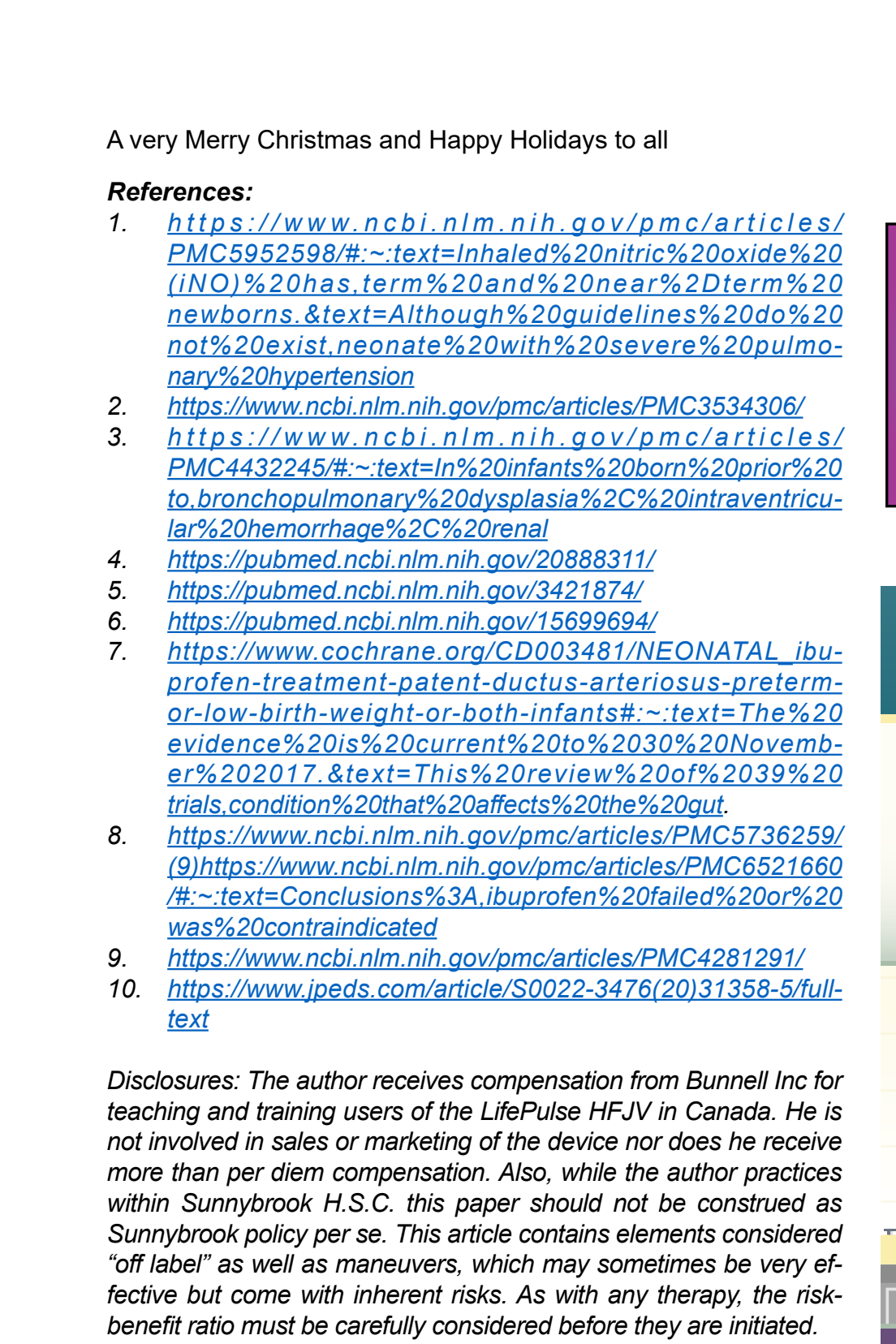

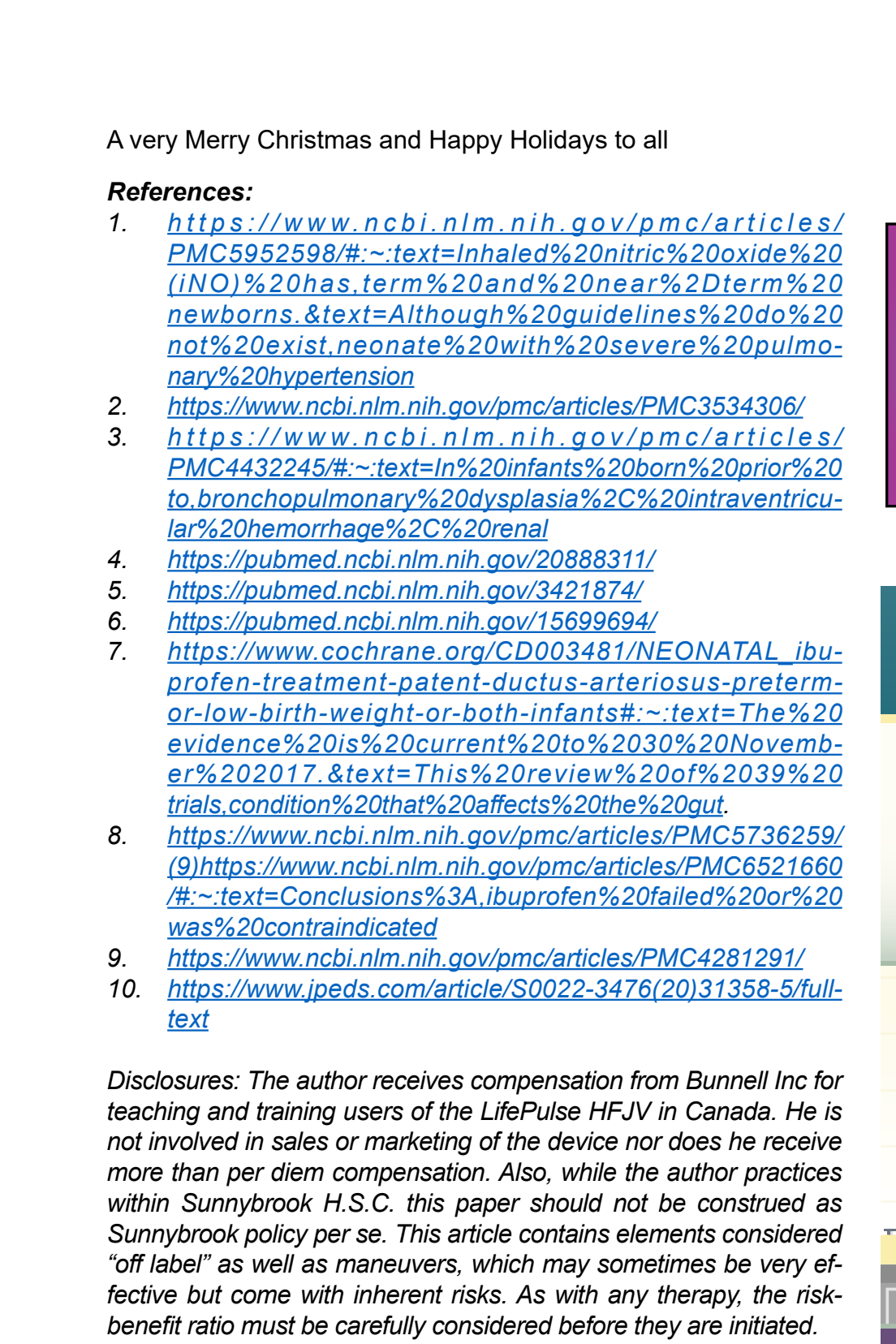

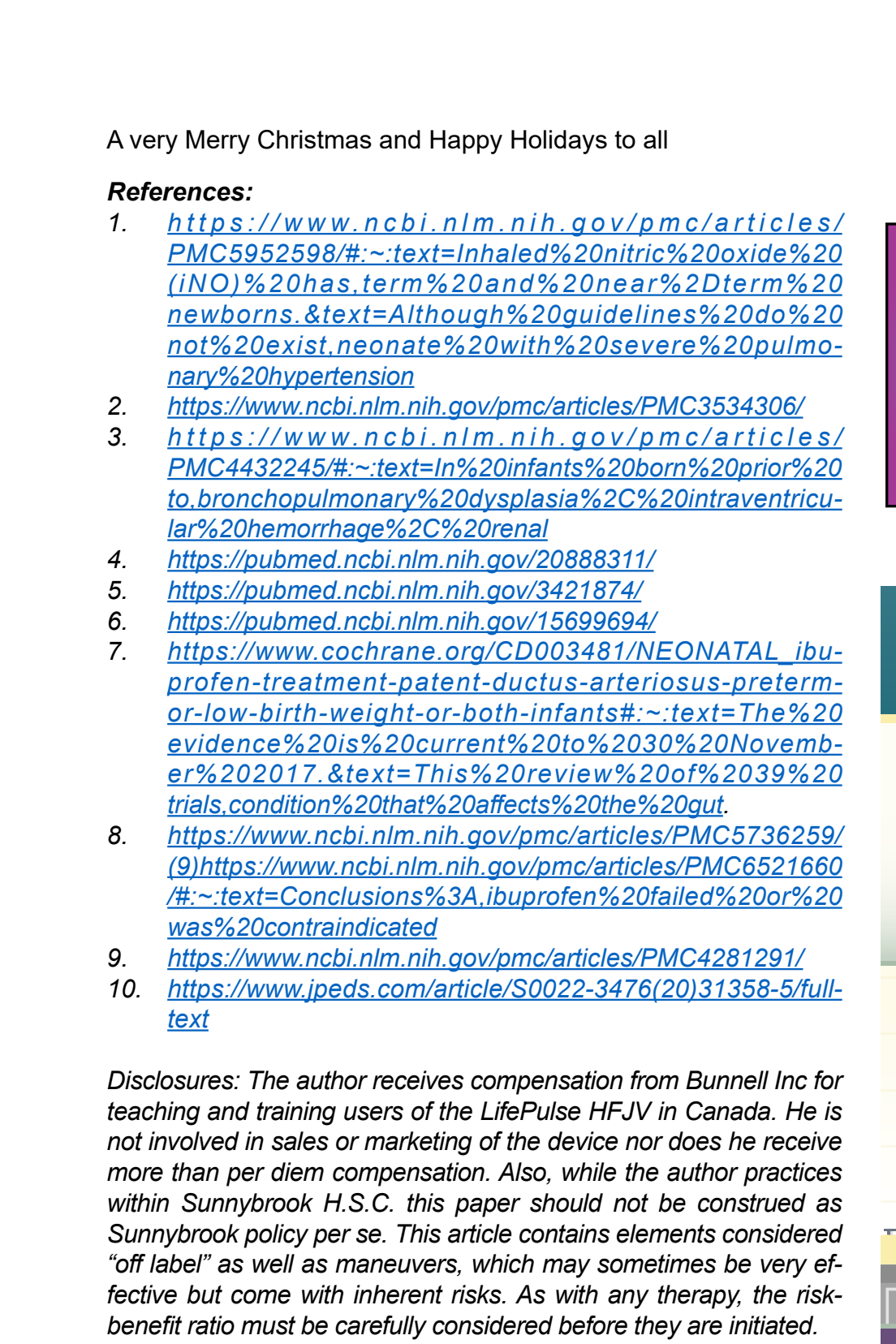

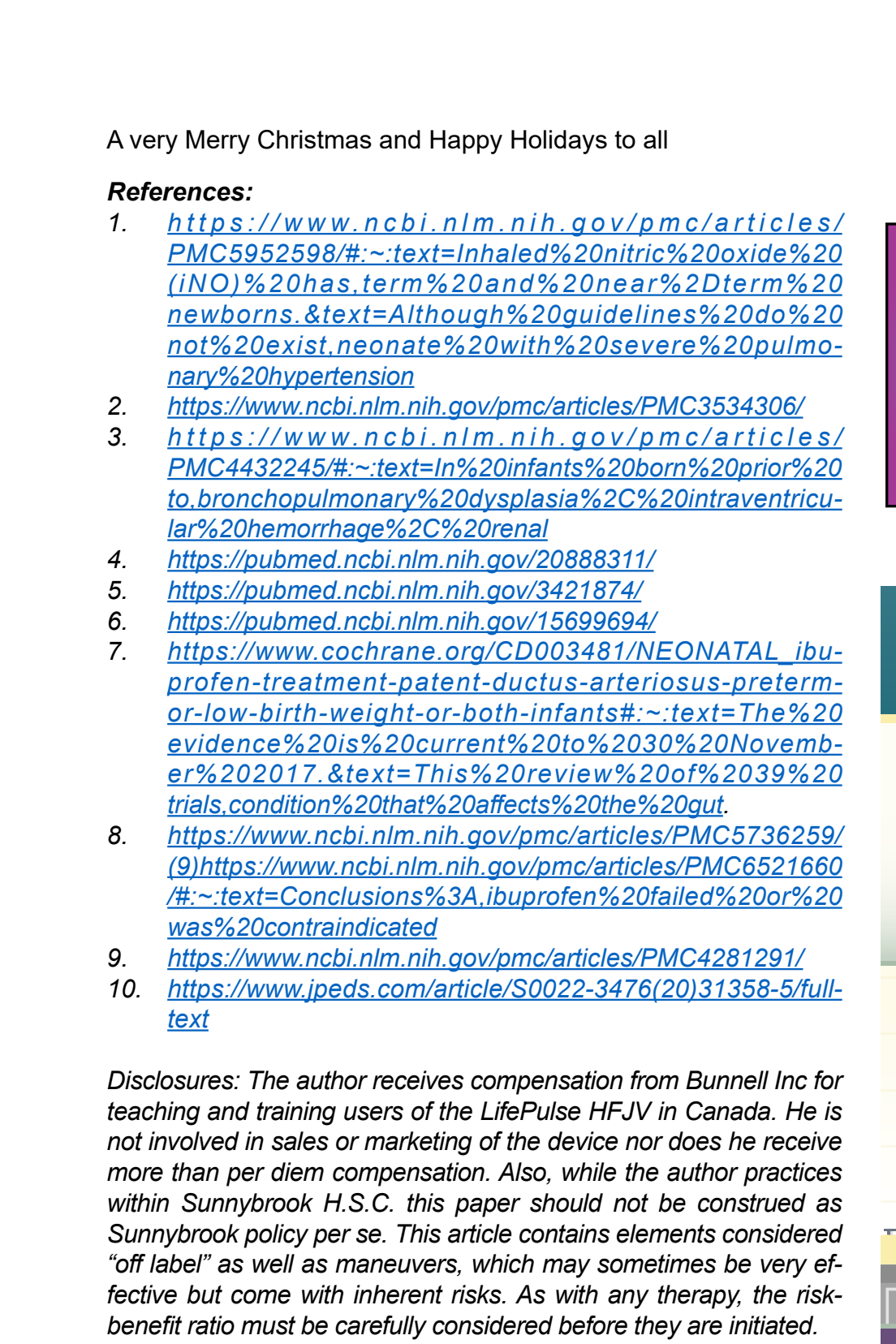

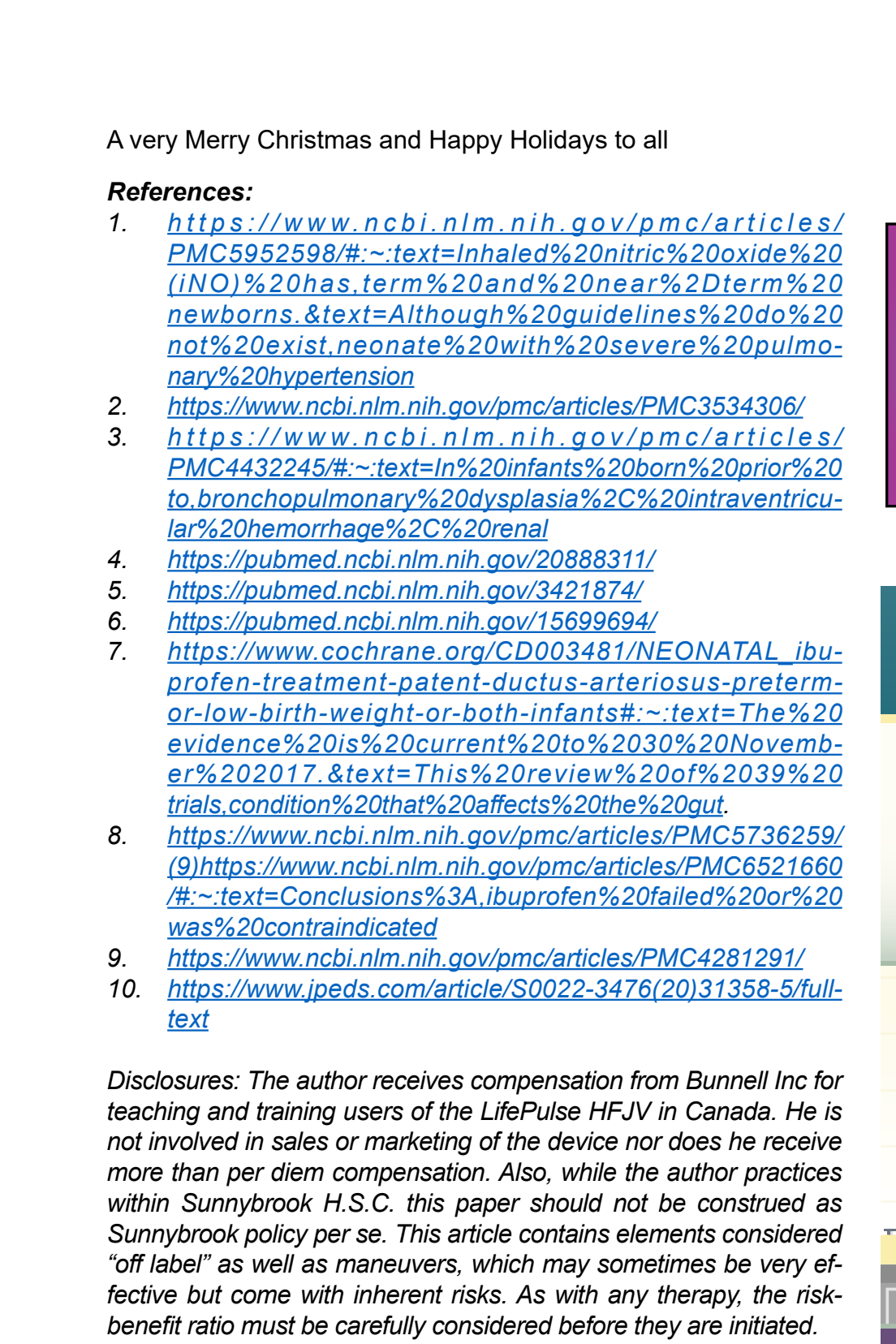

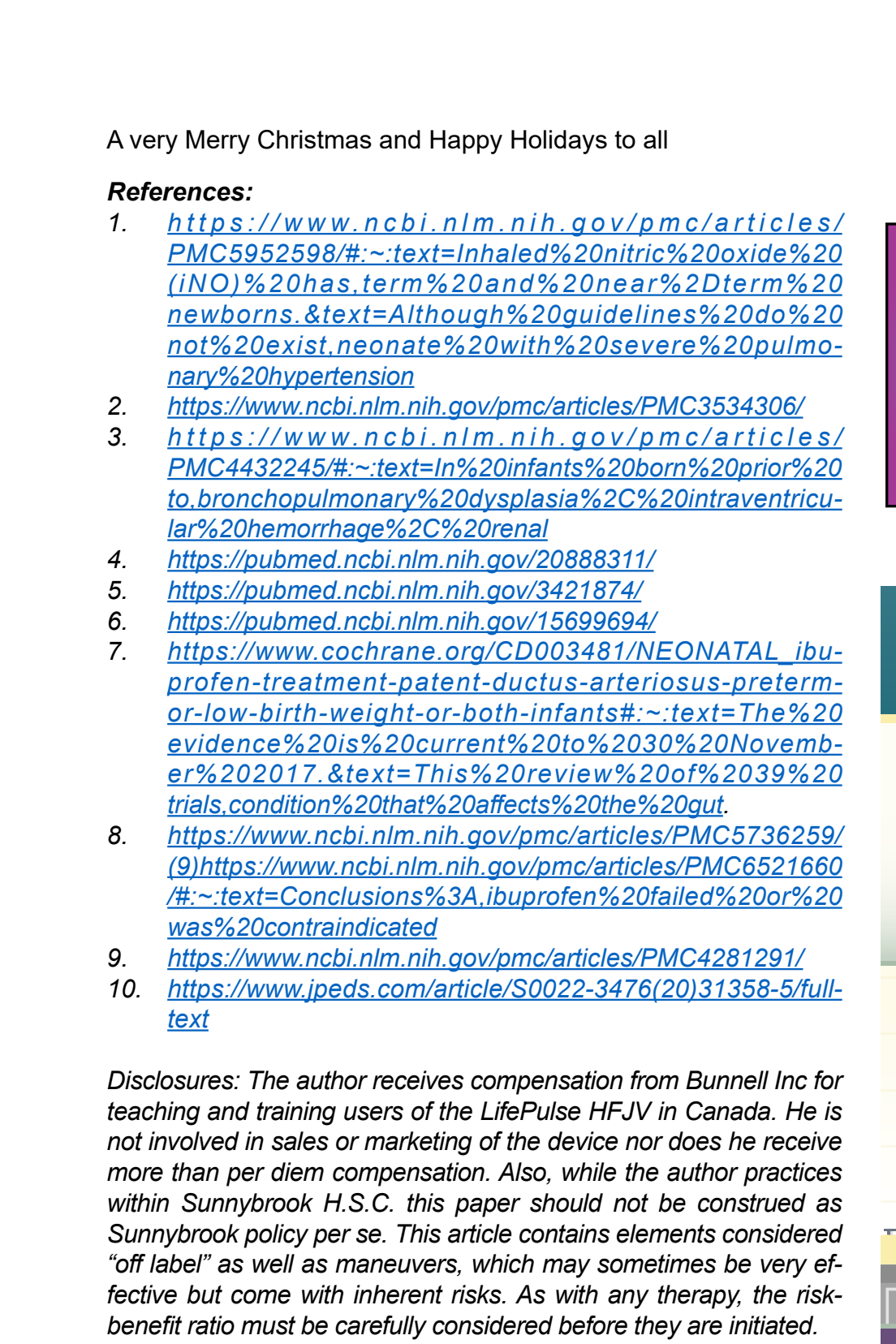

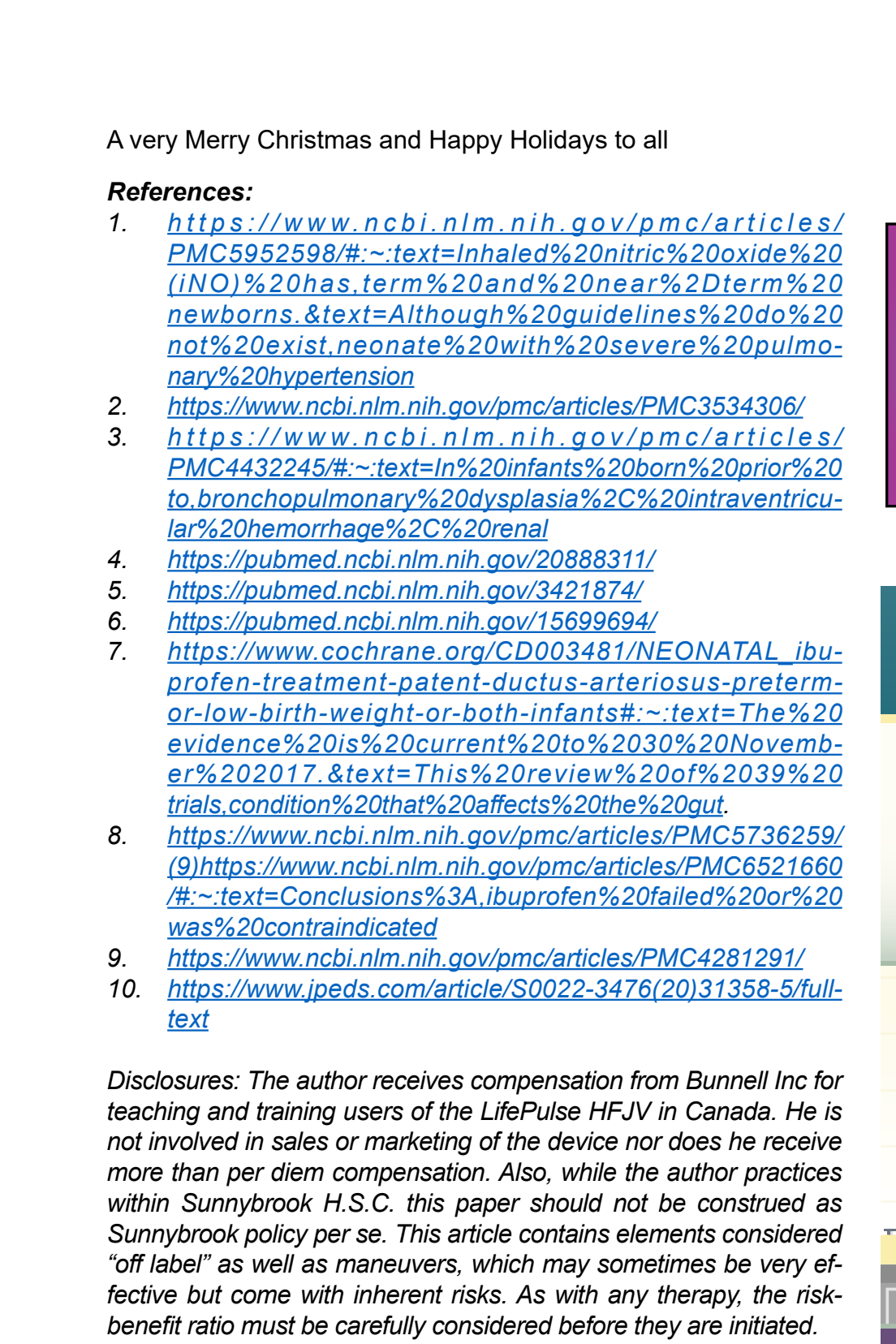

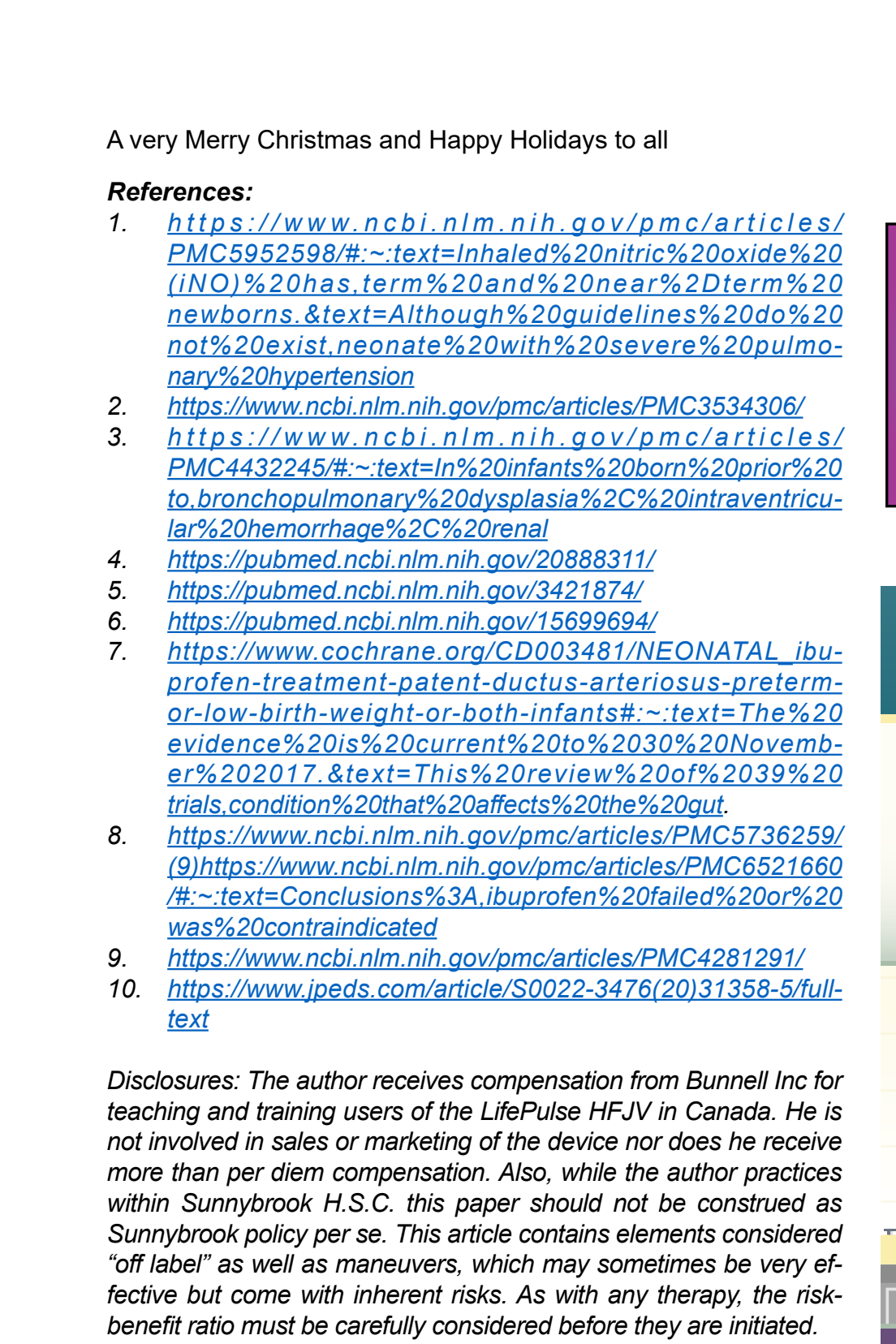

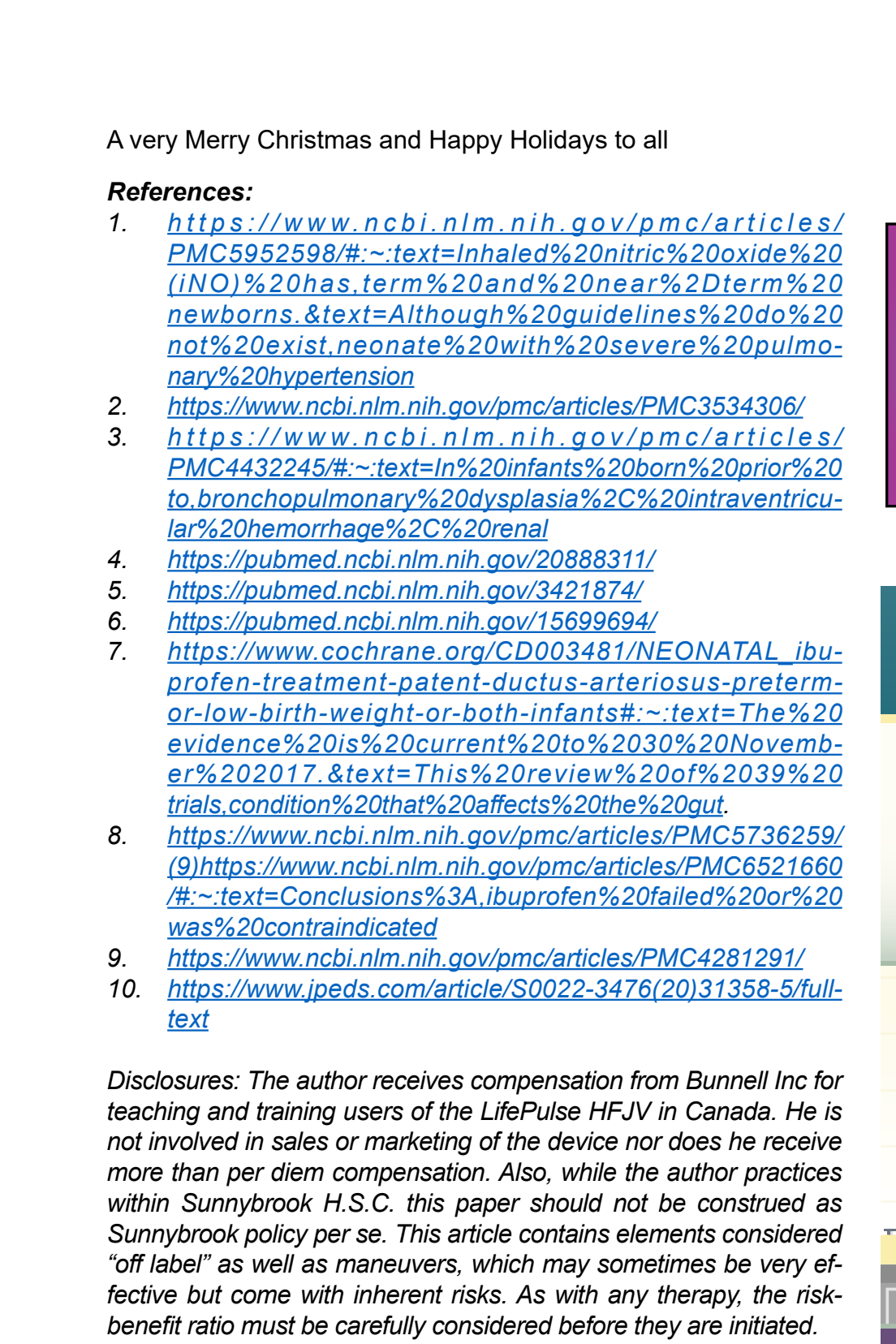

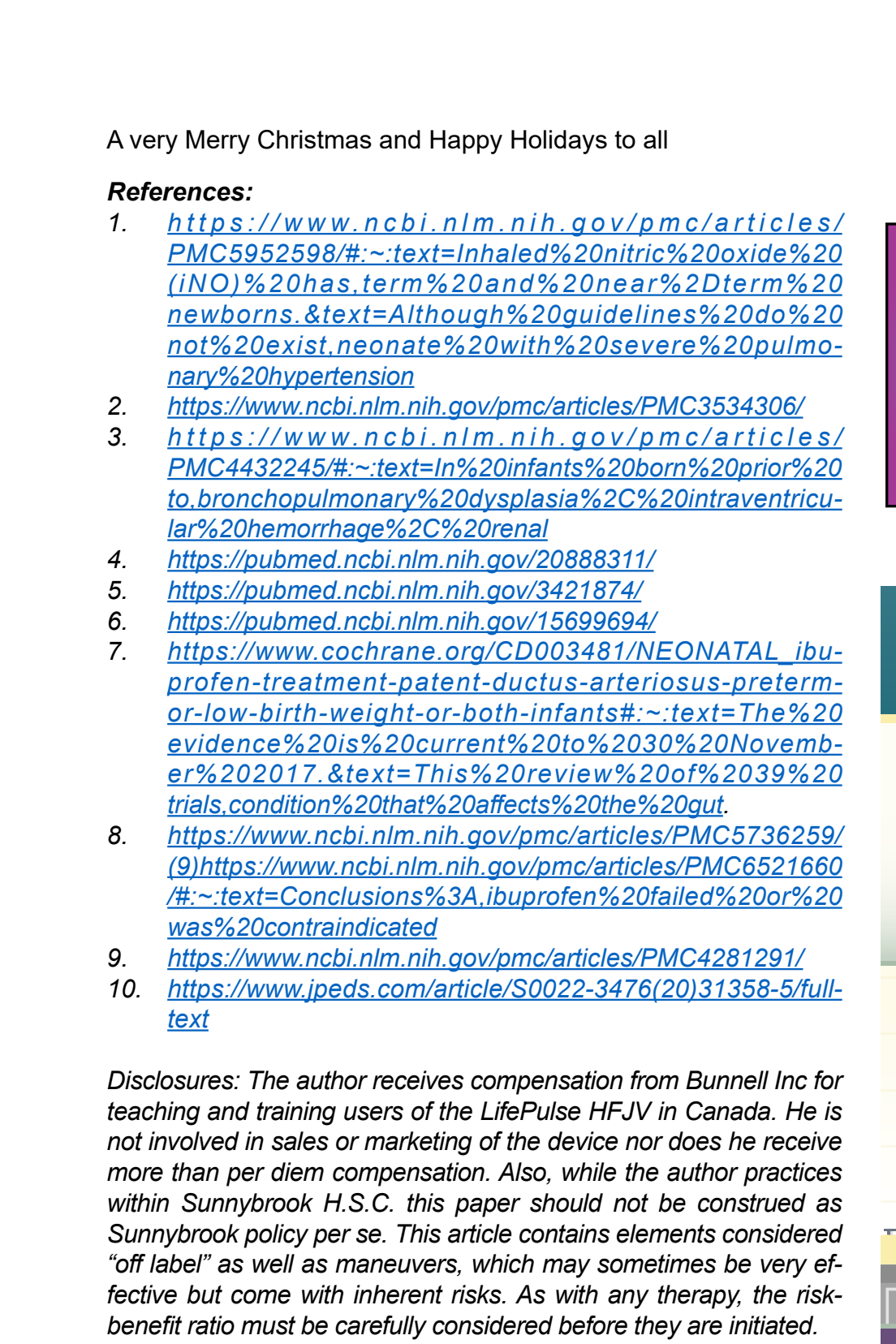

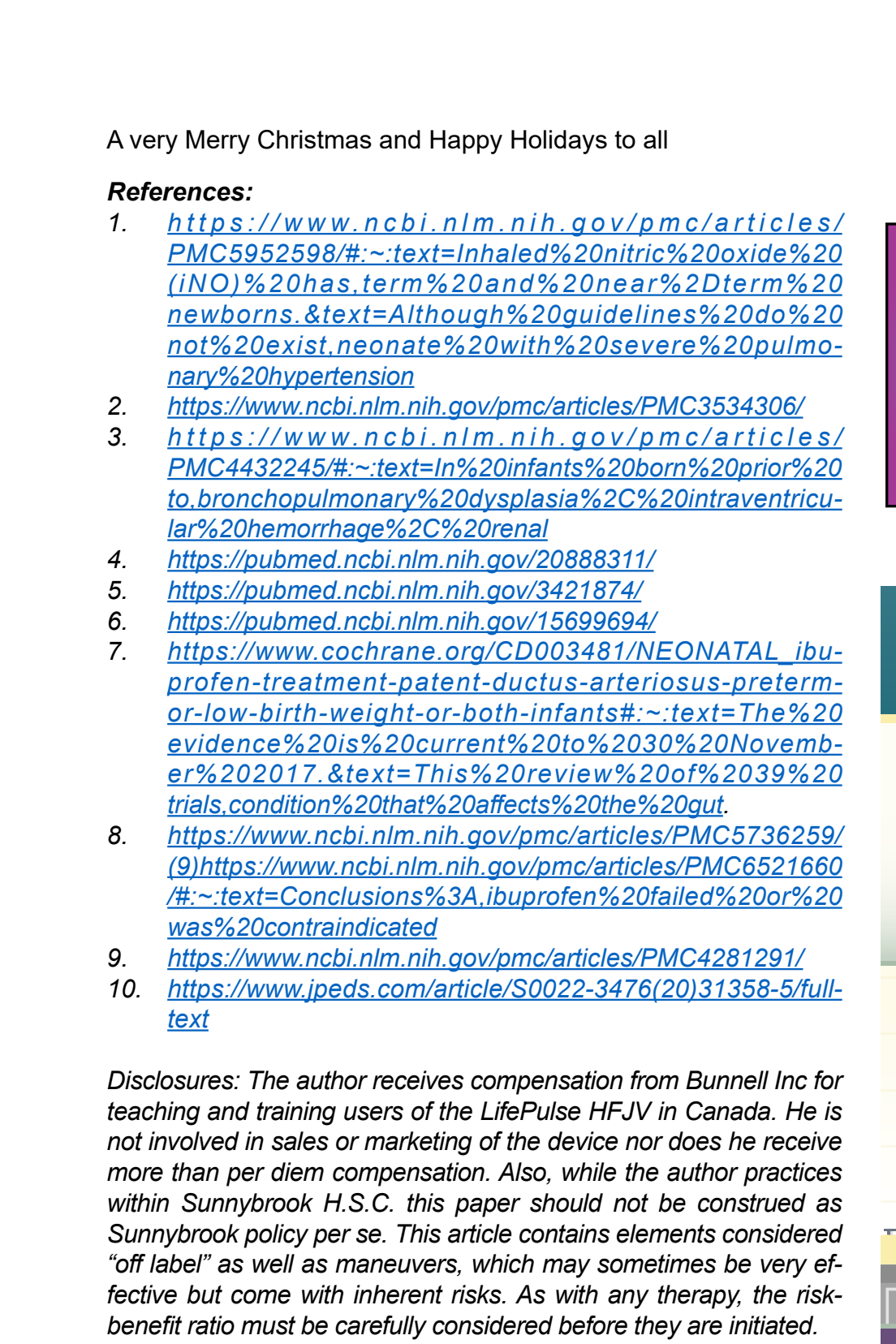

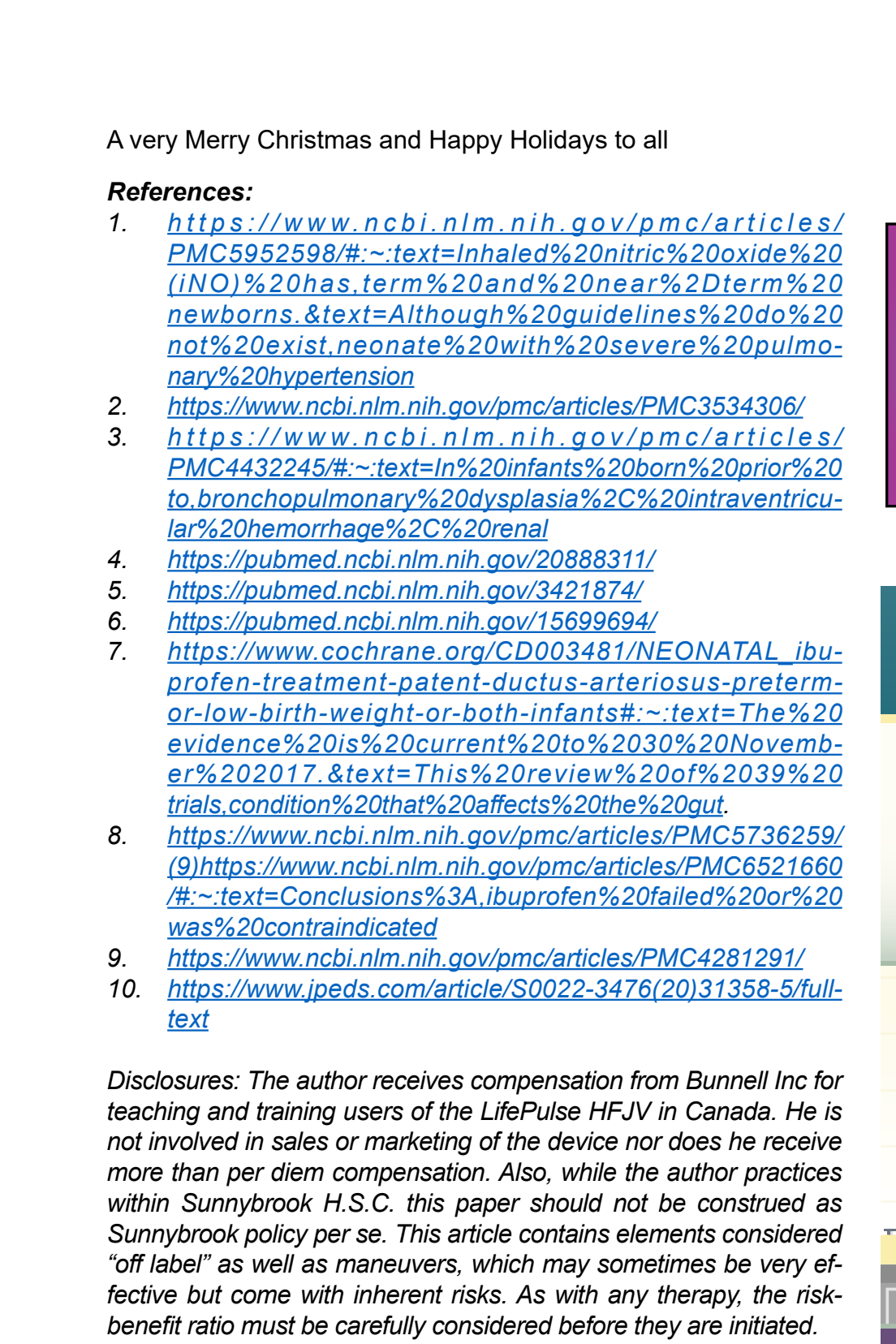

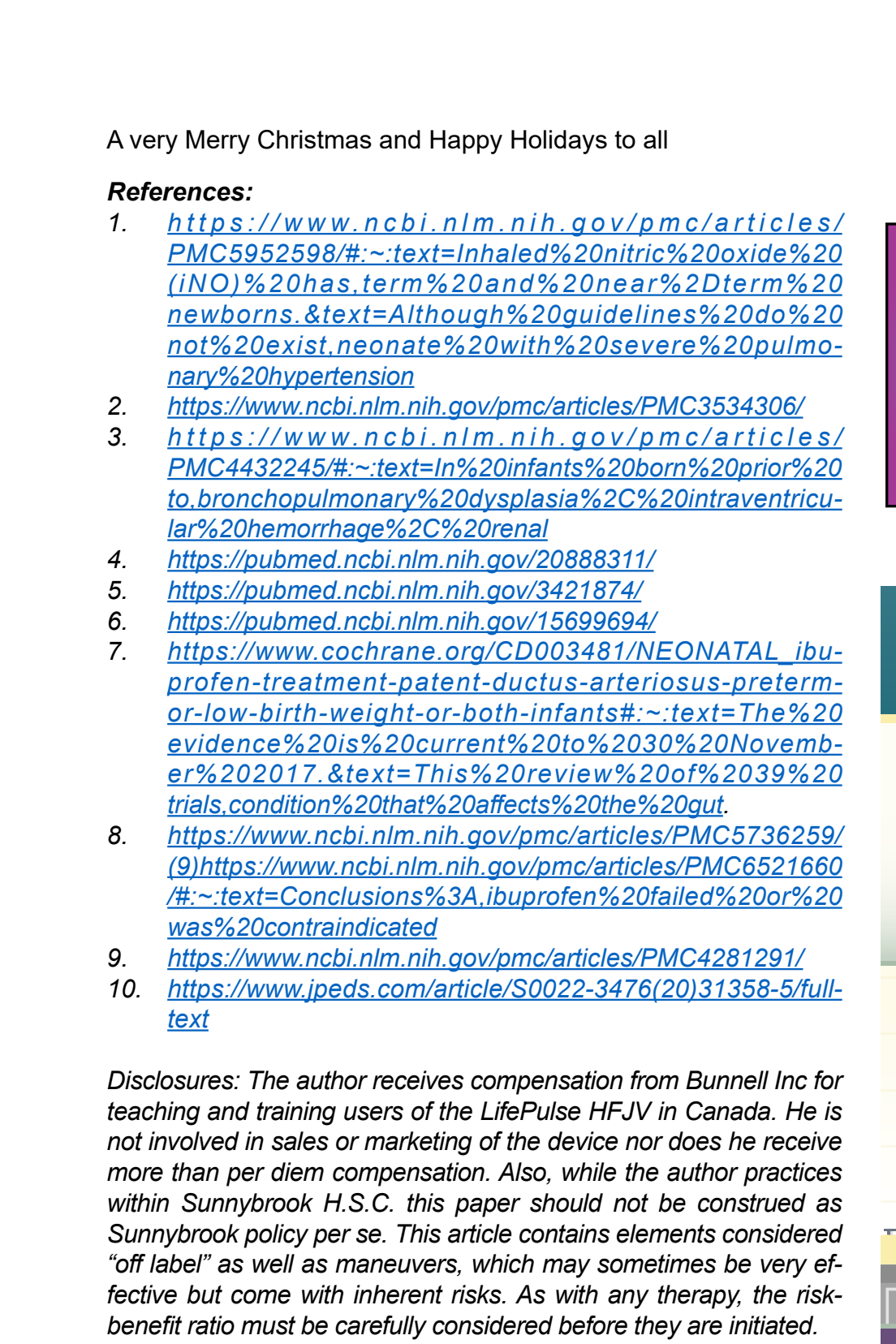

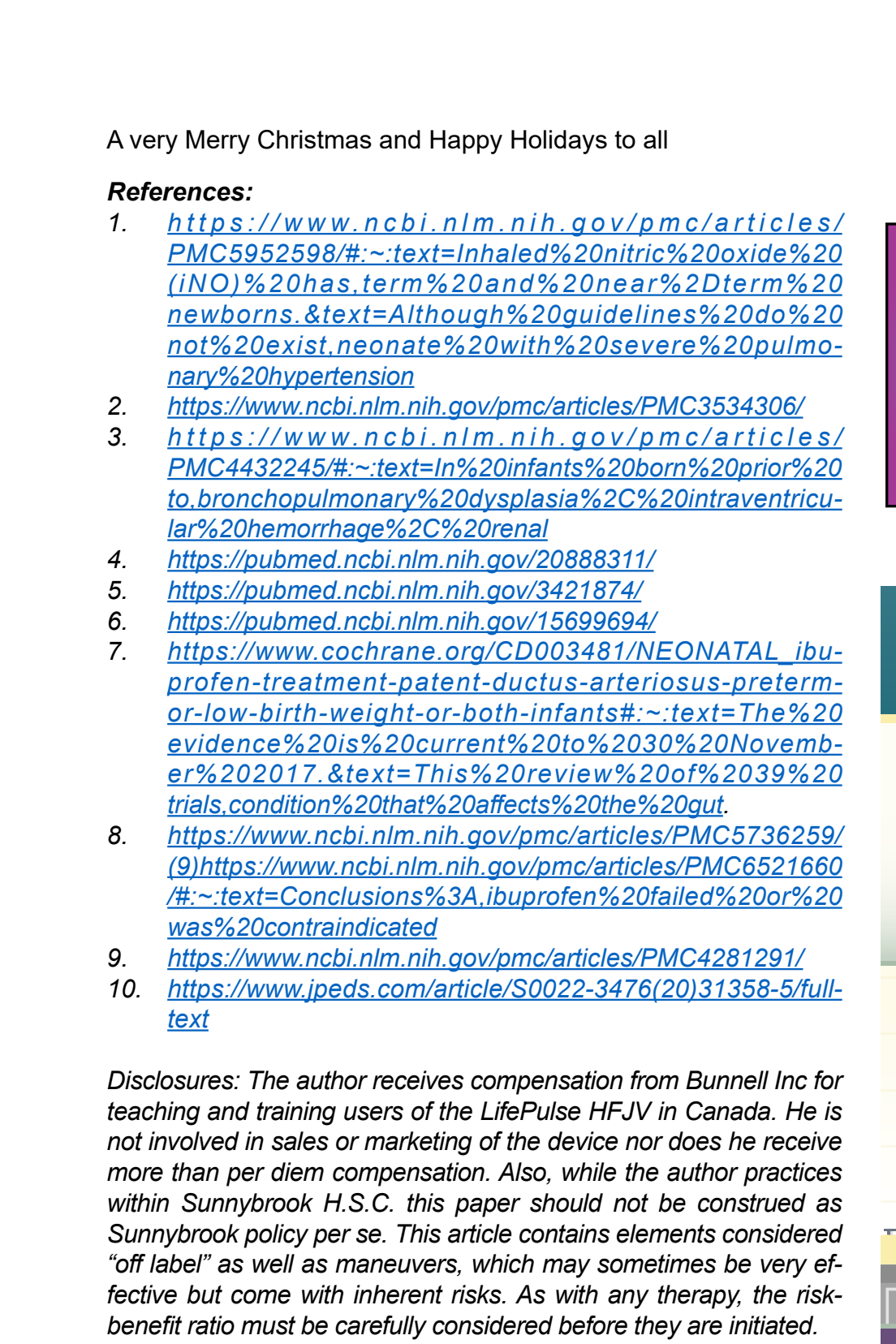

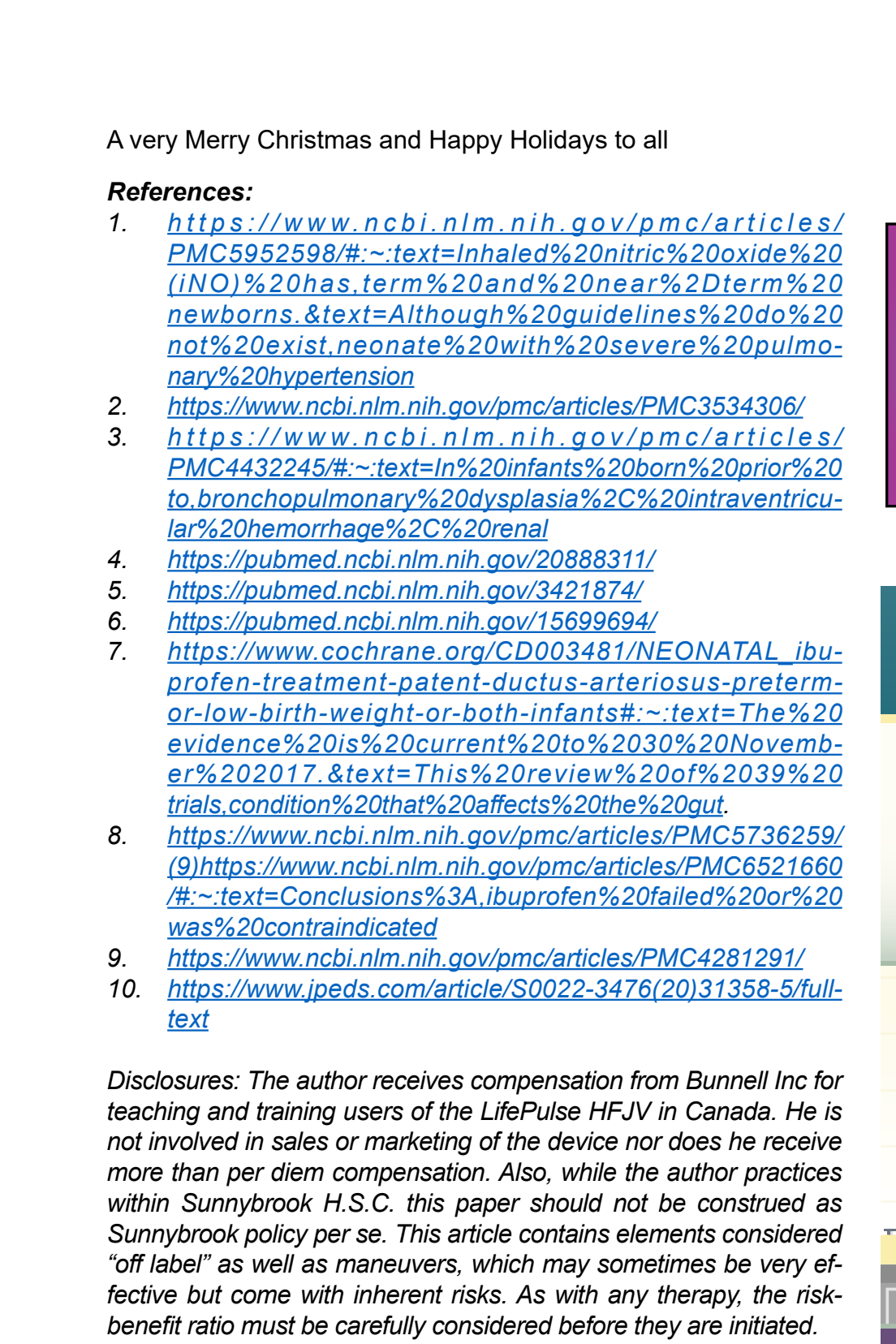

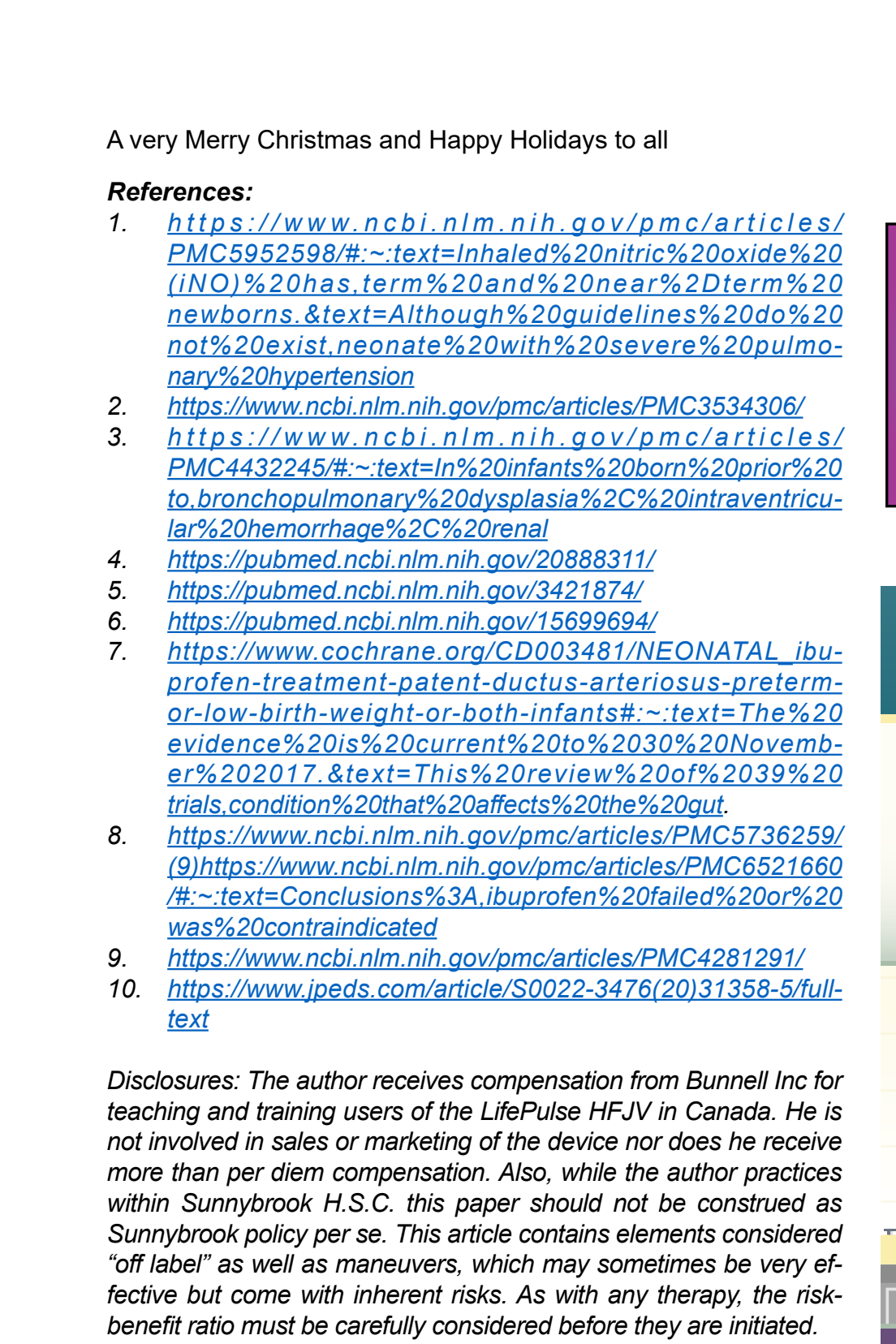

NT

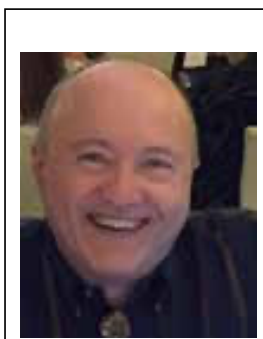

Corresponding Author

Rob Graham, R.R.T./N.R.C.P.

Advanced Practice Neonatal RRT

Sunnybrook Health Science Centre

43 Wellesley St. East

Toronto, ON

Canada M4Y $1 \mathrm{H1}$

Email: Rob Graham <rcgnrcp57@yahoo.ca>

Telephone: 416-967-8500

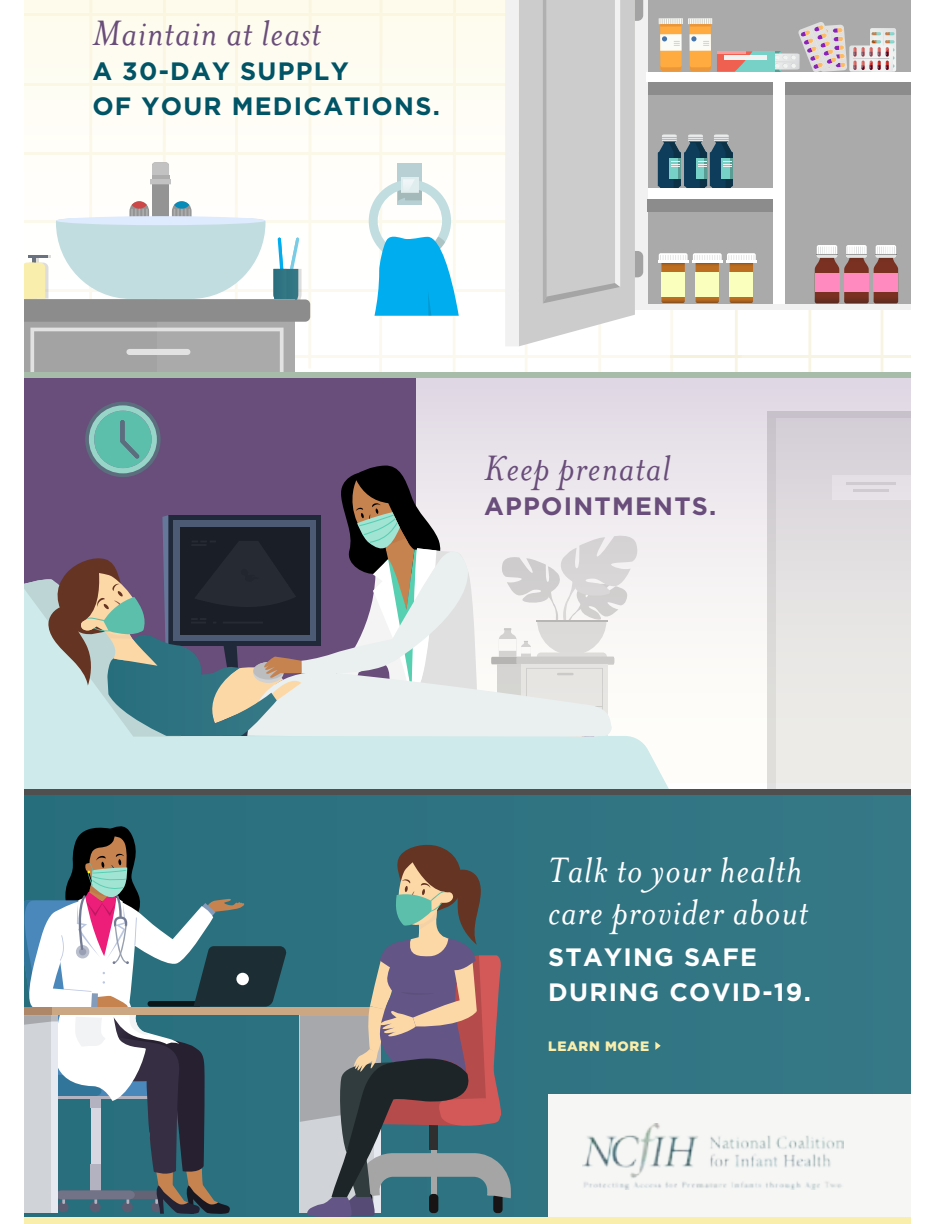

Maintain at least A 30-DAY SUPPLY OF YOUR MEDICATIONS
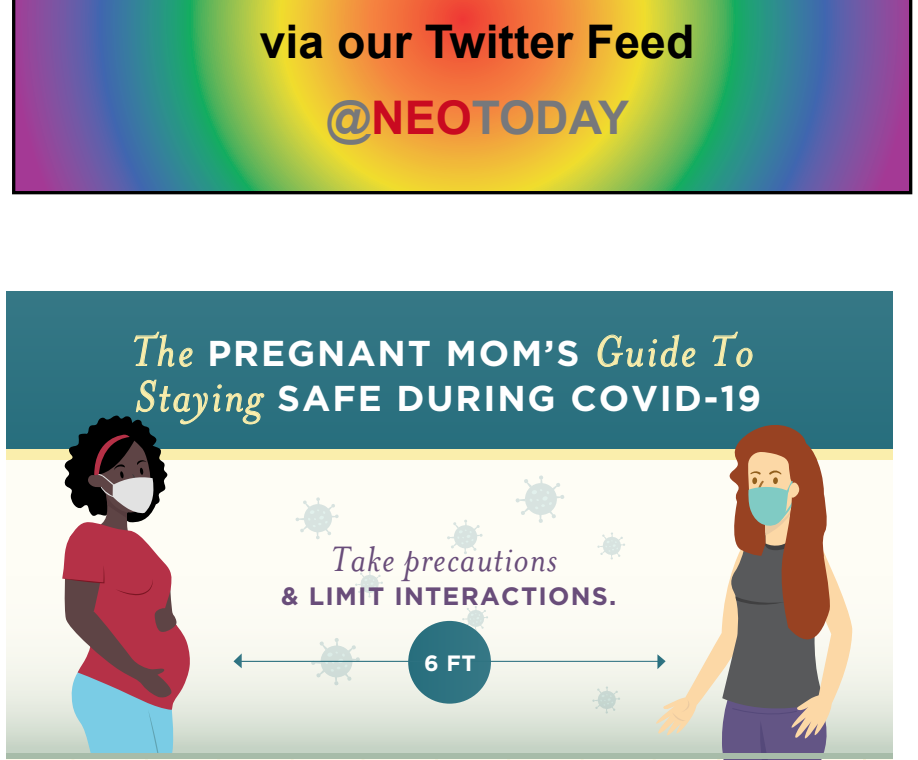

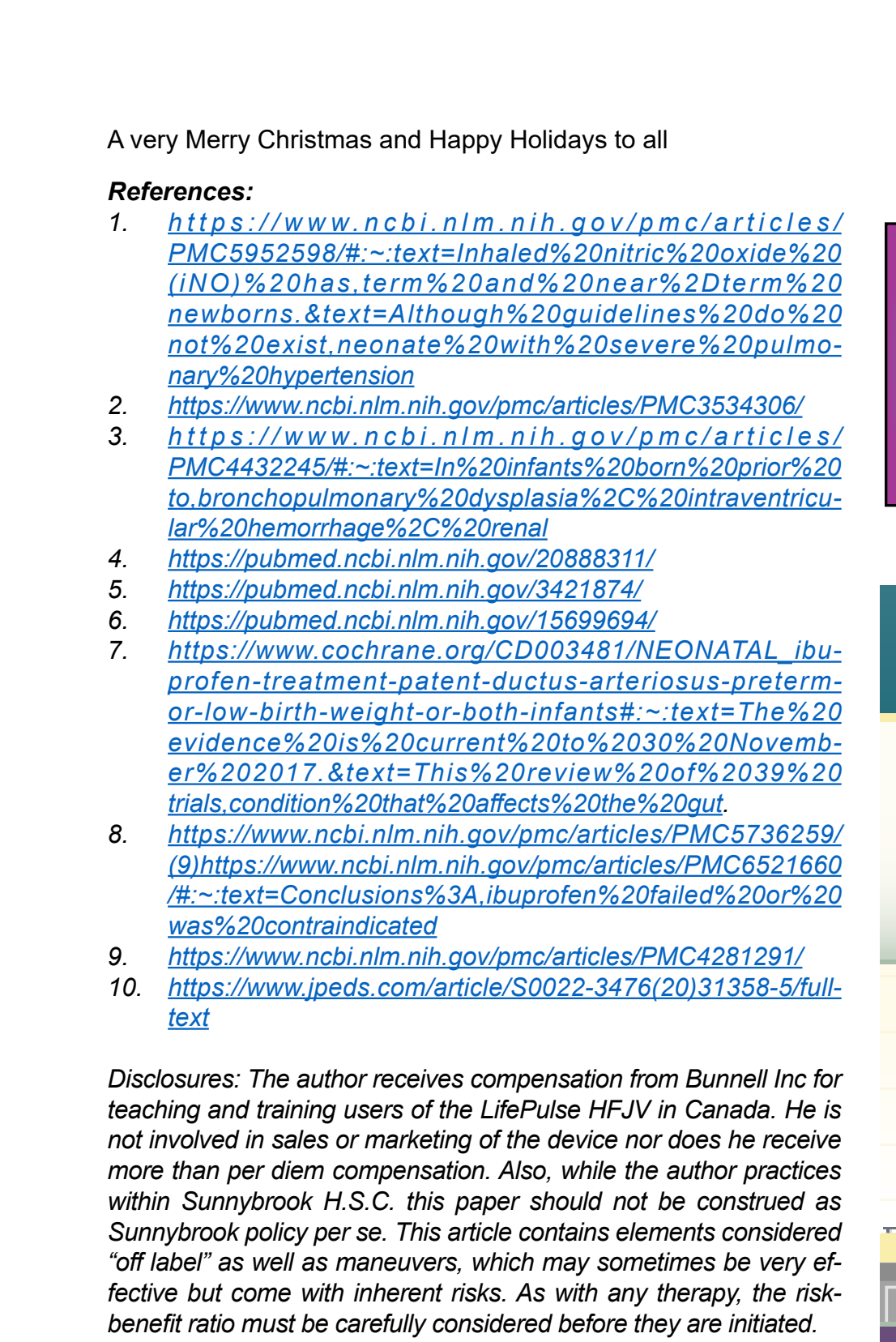

